Cochrane Database of Systematic Reviews

\title{
Corticosteroids for chronic inflammatory demyelinating polyradiculoneuropathy (Review)
}

Hughes RAC, Mehndiratta MM, Rajabally YA

Hughes RAC, Mehndiratta MM, Rajabally YA.

Corticosteroids for chronic inflammatory demyelinating polyradiculoneuropathy.

Cochrane Database of Systematic Reviews 2017, Issue 11. Art. No.: CD002062.

DOI: 10.1002/14651858.CD002062.pub4.

www.cochranelibrary.com 
TABLE OF CONTENTS

ABSTRACT 1

PLAIN LANGUAGE SUMMARY

SUMMARY OF FINDINGS

BACKGROUND

OBJECTIVES

METHODS

RESULTS

Figure 1.

Figure 2.

DISCUSSION

AUTHORS' CONCLUSIONS

ACKNOWLEDGEMENTS

REFERENCES

CHARACTERISTICS OF STUDIES

DATA AND ANALYSES

Analysis 1.1. Comparison 1 Corticosteroids versus control, Outcome 1 Improvement in impairment after 12 weeks excluding those who did not complete the study.

Analysis 1.2. Comparison 1 Corticosteroids versus control, Outcome 2 Improvement in impairment after 12 weeks including those who did not complete the study.

Analysis 1.3. Comparison 1 Corticosteroids versus control, Outcome 3 Number of patients improved after 12 weeks excluding those who did not complete the study.

Analysis 1.4. Comparison 1 Corticosteroids versus control, Outcome 4 Number of patients who showed improvement after 12 weeks including those who did not complete the study.

Analysis 2.1. Comparison 2 Standard-dose daily oral prednisolone versus monthly pulsed high-dose dexamethasone, Outcome 1 Remission at 12 months.

Analysis 2.2. Comparison 2 Standard-dose daily oral prednisolone versus monthly pulsed high-dose dexamethasone, Outcome $2 \geq 1$ point improvement on INCAT disability score at 12 months.

Analysis 2.3. Comparison 2 Standard-dose daily oral prednisolone versus monthly pulsed high-dose dexamethasone, Outcome 3 Change in MRC sum score at endpoint.

Analysis 2.4. Comparison 2 Standard-dose daily oral prednisolone versus monthly pulsed high-dose dexamethasone, Outcome 4 Change in grip strength at endpoint.

Analysis 2.5. Comparison 2 Standard-dose daily oral prednisolone versus monthly pulsed high-dose dexamethasone, Outcome 5 Sleeplessness.

Analysis 2.6. Comparison 2 Standard-dose daily oral prednisolone versus monthly pulsed high-dose dexamethasone, Outcome 6 Cushingoid facies.

Analysis 2.7. Comparison 2 Standard-dose daily oral prednisolone versus monthly pulsed high-dose dexamethasone, Outcome 7 Weight gain $1-3 \mathrm{~kg}$.

Analysis 2.8. Comparison 2 Standard-dose daily oral prednisolone versus monthly pulsed high-dose dexamethasone, Outcome 8 Weight gain $>3 \mathrm{~kg}$.

APPENDICES

WHAT'S NEW

HISTORY

CONTRIBUTIONS OF AUTHORS

DECLARATIONS OF INTEREST

SOURCES OF SUPPORT

DIFFERENCES BETWEEN PROTOCOL AND REVIEW

INDEX TERMS 
[Intervention Review]

\section{Corticosteroids for chronic inflammatory demyelinating polyradiculoneuropathy}

Richard AC Hughes ${ }^{1}$, Man Mohan Mehndiratta ${ }^{2}$, Yusuf A Rajabally ${ }^{3}$

1MRC Centre for Neuromuscular Diseases, National Hospital for Neurology and Neurosurgery, London, UK. 2Department of Neurology, Janakpuri Superspecialty Hospital, New Delhi, India. ${ }^{3}$ Aston Brain Centre, Aston University, Birmingham, UK

Contact: Richard AC Hughes, MRC Centre for Neuromuscular Diseases, National Hospital for Neurology and Neurosurgery, PO Box 114, Queen Square, London,WC1N 3BG, UK.rhughes11@btinternet.com, richard.hughes@ucl.ac.uk.

Editorial group: Cochrane Neuromuscular Group.

Publication status and date: Edited (no change to conclusions), published in Issue 10, 2019.

Citation: Hughes RAC, Mehndiratta MM, Rajabally YA. Corticosteroids for chronic inflammatory demyelinating polyradiculoneuropathy. Cochrane Database of Systematic Reviews 2017, Issue 11. Art. No.: CD002062. DOI: 10.1002/14651858.CD002062.pub4.

Copyright ( 2019 The Cochrane Collaboration. Published by John Wiley \& Sons, Ltd.

\section{A B S T R A C T}

\section{Background}

Chronic inflammatory demyelinating polyradiculoneuropathy (CIDP) is a progressive or relapsing and remitting paralysing illness, probably due to an autoimmune response, which should benefit from corticosteroid treatment. Non-randomised studies suggest that corticosteroids are beneficial. Two commonly used corticosteroids are prednisone and prednisolone. Both are usually given as oral tablets. Prednisone is converted into prednisolone in the liver so that the effect of the two drugs is usually the same. Another corticosteroid, dexamethasone, is more potent and is used in smaller doses. The review was first published in 2001 and last updated in 2015; we undertook this update to identify any new evidence.

\section{Objectives}

To assess the effects of corticosteroid treatment for CIDP compared to placebo or no treatment, and to compare the effects of different corticosteroid regimens.

\section{Search methods}

On 8 November 2016, we searched the Cochrane Neuromuscular Specialised Register, Cochrane Central Register of Controlled Trials, MEDLINE, and Embase for randomised trials of corticosteroids for CIDP. We searched clinical trials registries for ongoing trials.

\section{Selection criteria}

We included randomised controlled trials (RCTs) or quasi-RCTs of treatment with any corticosteroid or adrenocorticotrophic hormone for CIDP, diagnosed by an internationally accepted definition.

\section{Data collection and analysis}

Two authors extracted data from included studies and assessed the risk of bias independently. The intended primary outcome was change in disability, with change in impairment after 12 weeks and side effects as secondary outcomes. We assessed strength of evidence using the GRADE approach.

\section{Main results}

One non-blinded RCT comparing prednisone with no treatment in 35 eligible participants did not measure the primary outcome for this systematic review. The trial had a high risk of bias. Neuropathy Impairment Scale scores after 12 weeks improved in 12 of 19 participants randomised to prednisone, compared with five of 16 participants randomised to no treatment (risk ratio (RR) for improvement 2.02 ( $95 \%$ 
confidence interval ( $\mathrm{Cl}) 0.90$ to 4.52; very low-quality evidence). The trial did not report side effects in detail, but one prednisone-treated participant died.

A double-blind RCT comparing daily standard-dose oral prednisolone with monthly high-dose oral dexamethasone in 40 participants reported none of the prespecified outcomes for this review. The trial had a low risk of bias, but the quality of evidence was limited as it came from a single small study. There was little or no difference in number of participants who achieved remission (RR 1.11; $95 \% \mathrm{Cl}$ 0.50 to 2.45 in favour of monthly dexamethasone; moderate-quality evidence), or change in disability or impairment after one year (lowquality evidence). Change of grip strength or Medical Research Council (MRC) scores demonstrated little or no difference between groups (moderate-quality to low-quality evidence). Eight of 16 people in the prednisolone group and seven of 24 people in the dexamethasone group deteriorated. Side effects were similar with each regimen, except that sleeplessness was less common with monthly dexamethasone (low-quality evidence) as was moon facies (moon-shaped appearance of the face) (moderate-quality evidence).

Experience from large non-randomised studies suggests that corticosteroids are beneficial, but long-term use causes serious side effects.

\section{Authors' conclusions}

We are very uncertain about the effects of oral prednisone compared with no treatment, because the quality of evidence from the only RCT that exists is very low. Nevertheless, corticosteroids are commonly used in practice, supported by very low-quality evidence from observational studies. We also know from observational studies that corticosteroids carry the long-term risk of serious side effects. The efficacy of high-dose monthly oral dexamethasone is probably little different from that of daily standard-dose oral prednisolone. Most side effects occurred with similar frequencies in both groups, but with high-dose monthly oral dexamethasone moon facies is probably less common and sleeplessness may be less common than with oral prednisolone. We need further research to identify factors that predict response.

\section{PLAIN LANGUAGE SUMMARY}

\section{Corticosteroids for chronic inflammatory demyelinating polyradiculoneuropathy}

\section{Review question}

We reviewed the evidence about the benefits and harms of using corticosteroids for the treatment of chronic inflammatory demyelinating polyradiculoneuropathy (CIDP).

\section{Background}

CIDP is an uncommon paralysing disease that occurs when nerves outside the brain and spinal cord become inflamed. It produces slowly evolving weakness and numbness of the limbs. Some people have recurrent periods of worsening followed by improvement or remission. We wanted to discover the answers to two questions: firstly, whether use of corticosteroids is helpful; and secondly, whether one type of corticosteroid treatment is better than another. This is an update of a review first published in 2001 and last updated in 2014.

\section{Study characteristics}

We found one randomised controlled trial (RCT) addressing each question. We did not find any new trials for this update.

A 1982 US study compared daily prednisone tablets for 12 weeks with no treatment. Thirty-five people took part. Fourteen participants received prednisone (10 male and four female, with a median age of 46.5 years) and 14 did not receive prednisone (nine male and five female, with a median age of 50 years). Those taking part and the trialists were aware of which treatment the participants received (i.e. they were not 'blinded'), which carries a risk of bias.

The second study compared two six-month corticosteroid treatment regimens: daily standard-dose prednisolone tablets, and high-dose dexamethasone tablets for four days each month. Multiple European centres did the trial, which reported its findings in 2010. Forty-one people took part but one person withdrew after one day because they did not want to continue and the diagnosis was wrong. Of those who continued, 24 ( 18 men and six women, average age 59.9 years) received monthly dexamethasone and 16 ( 10 men and six women, average age 60.8 years) received daily prednisolone.

There was no commercial support for either study. Funding for both came from an academic centre or charitable funds.

\section{Key results}

Neither included study reported our preferred primary outcome, which was a disability score.

After 12 weeks, in the trial of prednisone compared to no treatment, 12 of 19 participants on prednisone improved compared with five of 16 participants not on prednisone, based on measurement of disease severity by neurologists. Thus, improvement was about twice as common with prednisone. The small numbers in the trial and its limitations meant that even with this difference we are very uncertain about the size of any effect of prednisone. The trial authors did not report side effects in detail, but one person who received prednisone 
died. Corticosteroids are commonly used for CIDP in practice, based on favourable reports from non-randomised studies. Corticosteroids are well known to cause side effects, especially when people take large doses for a long time.

In the RCT comparing two corticosteroid regimens, 10 of 24 people on monthly dexamethasone and six of 16 people on daily prednisolone were well and off treatment after a year, which indicates effects that are probably similar. Changes in grip strength and scores of muscle strength were also probably similar between the treatment groups. Monthly dexamethasone and daily prednisolone had similar side effects to one another, except that with high-dose monthly dexamethasone, sleeplessness may be less common and a moon-shaped facial appearance is probably less common.

\section{Quality of the evidence}

The benefit and harm from prednisone in CIDP is uncertain. The quality of evidence is very low because only one small randomised trial with a high risk of bias is available.

Monthly dexamethasone and daily prednisolone may be of similar benefit in CIDP, but monthly dexamethasone may have fewer side effects.

\section{Date}

The evidence is up to date to 8 November 2016. 
SUMMARY OF FINDINGS

Summary of findings for the main comparison. Prednisone for chronic inflammatory demyelinating polyradiculoneuropathy

Prednisone for chronic inflammatory demyelinating polyradiculoneuropathy

Patient or population: people with chronic inflammatory demyelinating polyradiculoneuropathy

Settings: hospital specialist neurological outpatient department

Intervention: prednisone

\begin{tabular}{|c|c|c|c|c|c|c|}
\hline \multirow[t]{3}{*}{ Outcomes } & \multicolumn{2}{|c|}{ Illustrative comparative risks* $(95 \% \mathrm{Cl})$} & \multirow{3}{*}{$\begin{array}{l}\text { Relative effect } \\
(95 \% \mathrm{CI})\end{array}$} & \multirow{3}{*}{$\begin{array}{l}\text { No of partici- } \\
\text { pants } \\
\text { (studies) }\end{array}$} & \multirow{3}{*}{$\begin{array}{l}\text { Quality of the } \\
\text { evidence } \\
\text { (GRADE) }\end{array}$} & \multirow[t]{3}{*}{ Comments } \\
\hline & Assumed risk or value & Corresponding risk or value & & & & \\
\hline & Control (no treatment) & Prednisone & & & & \\
\hline $\begin{array}{l}\text { Change in disability after one } \\
\text { year }\end{array}$ & - & - & - & - & - & Not measured \\
\hline $\begin{array}{l}\text { Change in impairment after } 12 \\
\text { weeks (including those who did } \\
\text { not complete the study) } \\
\text { NIS (range } 0 \text { to } 280 \text { ) }\end{array}$ & $\begin{array}{l}\text { The mean improvement } \\
\text { in impairment after } 12 \\
\text { weeks, including those } \\
\text { who did not complete } \\
\text { the study in the control } \\
\text { group was } \\
-2.4 \text { points (i.e. } 2.4 \\
\text { points worse) }\end{array}$ & $\begin{array}{l}\text { The mean improvement in } \\
\text { impairment after } 12 \text { weeks, } \\
\text { including those who did not } \\
\text { complete the study in the } \\
\text { prednisone group was } \\
\mathbf{1 1 . 6} \text { points higher } \\
\text { (9.39 lower to } 32.58 \text { higher) }\end{array}$ & - & $\begin{array}{l}35 \\
(1 \mathrm{RCT})\end{array}$ & $\begin{array}{l}\oplus \ominus \ominus \ominus \\
\text { Very low }{ }^{1}\end{array}$ & $\begin{array}{l}\text { Not statistically } \\
\text { significant }\end{array}$ \\
\hline $\begin{array}{l}\text { Number of participants im- } \\
\text { proved after } 12 \text { weeks (exclud- } \\
\text { ing those who did not complete } \\
\text { the study) } \\
\text { NIS score (range } 0 \text { to } 280 \text { ) }\end{array}$ & 357 per 1000 & $\begin{array}{l}857 \text { per } 1000 \\
\text { (411 to } 1000)\end{array}$ & $\begin{array}{l}\text { RR } 2.40 \\
\text { (Cl } 1.15 \text { to } 5)\end{array}$ & $\begin{array}{l}28 \\
(1 \mathrm{RCT})\end{array}$ & $\begin{array}{l}\oplus \odot \odot \ominus \\
\text { Very low } 1,2\end{array}$ & $\begin{array}{l}\text { Statistically sig- } \\
\text { nificant more } \\
\text { improvement, } \\
\text { but at high risk } \\
\text { of bias }\end{array}$ \\
\hline $\begin{array}{l}\text { Number of participants im- } \\
\text { proved after } 12 \text { weeks (includ- }\end{array}$ & 312 per 1000 & $\begin{array}{l}\mathbf{6 3 1} \text { per } 1000 \\
\text { (281 to } 1000)\end{array}$ & $\begin{array}{l}\text { RR } 2.02 \\
\text { (Cl } 0.9 \text { to } 4.52)\end{array}$ & $\begin{array}{l}35 \\
(1 \mathrm{RCT})\end{array}$ & $\begin{array}{l}\oplus \ominus \ominus \ominus \\
\text { Very low } 1,2\end{array}$ & $\begin{array}{l}\text { Not statistically } \\
\text { significant }\end{array}$ \\
\hline
\end{tabular}

Number of participants im

(281 to 1000$)$

(Cl 0.9 to 4.52 )

Very low 1,2

significant 
*The basis for the assumed risk (e.g. the median control group risk across studies) is provided in footnotes. The corresponding risk (and its $95 \%$ confidence interval) is based on the assumed risk in the comparison group and the relative effect of the intervention (and its $95 \% \mathrm{Cl}$ ).

Cl: confidence interval; NIS: Neuropathy Impairment Scale; RR: risk ratio

GRADE Working Group grades of evidence

High quality: Further research is very unlikely to change our confidence in the estimate of effect.

Moderate quality: Further research is likely to have an important impact on our confidence in the estimate of effect and may change the estimate.

Low quality: Further research is very likely to have an important impact on our confidence in the estimate of effect and is likely to change the estimate.

Very low quality: We are very uncertain about the estimate.

1We downgraded the quality of evidence three times: twice for very serious study limitations and once for imprecision. The trial was not blinded and randomisation was not concealed. The $95 \% \mathrm{Cl}$ were wide.

2Seven participants were excluded, giving high risk of bias in favour of prednisone.

Summary of findings 2 . Monthly pulsed high-dose dexamethasone compared to oral prednisolone for chronic inflammatory demyelinating polyradiculoneuropathy

Monthly pulsed high-dose dexamethasone compared to oral prednisolone for chronic inflammatory demyelinating polyradiculoneuropathy

Patient or population: people with chronic inflammatory demyelinating polyradiculoneuropathy

Settings: hospital specialist neurological outpatient department

Intervention: monthly pulsed high-dose dexamethasone

Comparison: oral prednisolone

\begin{tabular}{|c|c|c|c|c|c|c|}
\hline \multirow[t]{2}{*}{ Outcomes } & \multicolumn{2}{|c|}{ Illustrative comparative risks* $(95 \% \mathrm{Cl})$} & \multirow{2}{*}{$\begin{array}{l}\text { Relative effect } \\
(95 \% \mathrm{CI})\end{array}$} & \multirow{2}{*}{$\begin{array}{l}\text { No of partici- } \\
\text { pants } \\
\text { (studies) }\end{array}$} & \multirow{2}{*}{$\begin{array}{l}\text { Quality of the } \\
\text { evidence } \\
\text { (GRADE) }\end{array}$} & \multirow[t]{2}{*}{ Comments } \\
\hline & Assumed risk or value & Corresponding risk or value & & & & \\
\hline $\begin{array}{l}\text { Change in disability } \\
\text { after one year }\end{array}$ & - & - & - & - & - & Not measured \\
\hline $\begin{array}{l}\text { Remission at } 12 \\
\text { months }\end{array}$ & 375 per 1000 & $\begin{array}{l}\mathbf{4 1 6} \text { per } \mathbf{1 0 0 0} \\
\text { (188 to } 919)\end{array}$ & $\begin{array}{l}\text { RR } 1.11 \\
\text { (Cl } 0.5 \text { to } 2.45)\end{array}$ & $\begin{array}{l}40 \\
(1 \mathrm{RCT})\end{array}$ & $\begin{array}{l}\oplus \oplus \oplus \ominus \\
\text { Moderate } 1\end{array}$ & Not significant \\
\hline $\begin{array}{l}\geq 1 \text { point improve- } \\
\text { ment on INCAT dis- }\end{array}$ & 438 per 1000 & $\begin{array}{l}\mathbf{5 4 2} \text { per } \mathbf{1 0 0 0} \\
(280 \text { to } 1000)\end{array}$ & $\begin{array}{l}\text { RR } 1.24 \\
\text { (Cl } 0.64 \text { to } 2.41 \text { ) }\end{array}$ & $\begin{array}{l}40 \\
(1 \mathrm{RCT})\end{array}$ & $\begin{array}{l}\oplus \oplus \ominus \ominus \\
\text { Low }^{2}\end{array}$ & Not significant \\
\hline
\end{tabular}




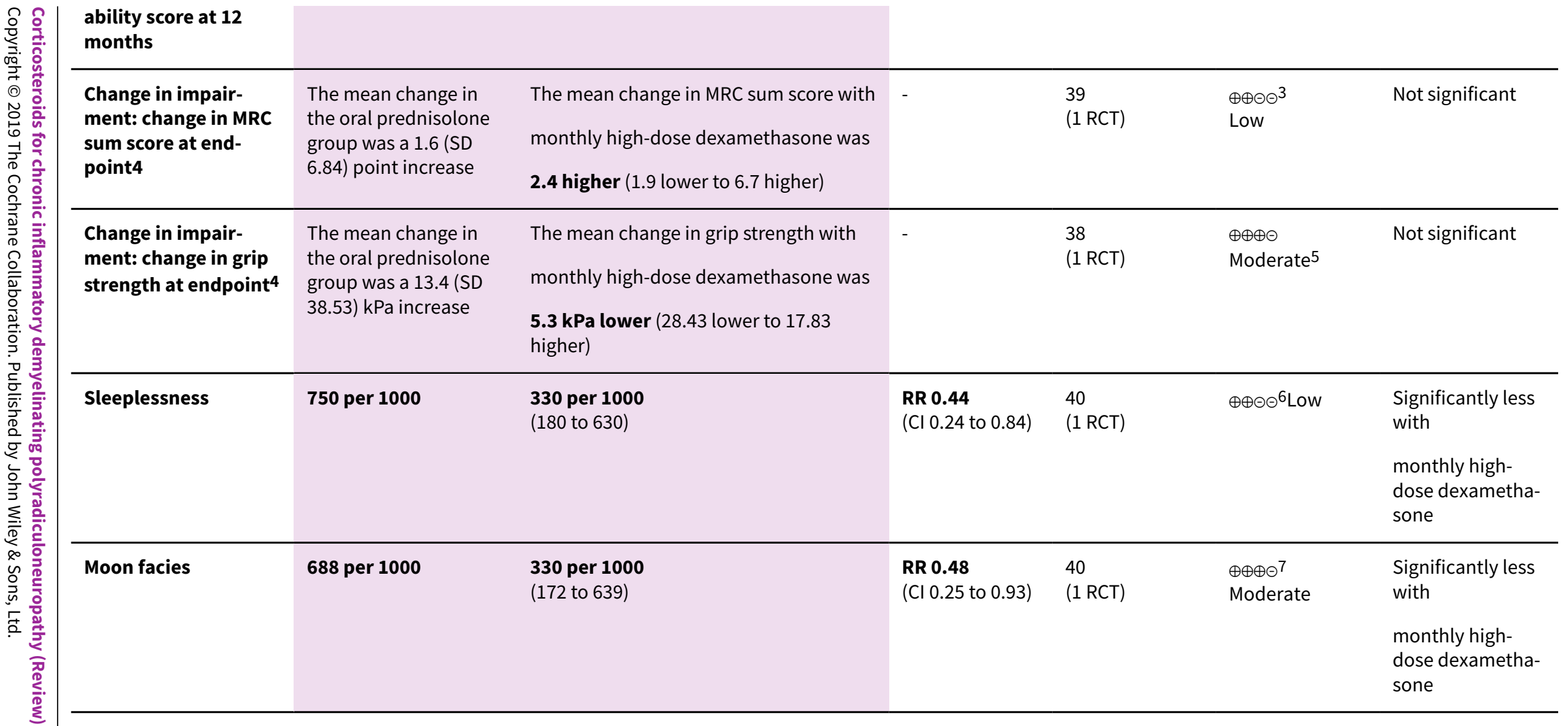

*The basis for the assumed risk (e.g. the median control group risk across studies) is provided in footnotes. The corresponding risk (and its $95 \%$ confidence interval) is based on the assumed risk in the comparison group and the relative effect of the intervention (and its $95 \% \mathrm{Cl}$ ).

CI: confidence interval; INCAT: Inflammatory Neuropathy Cause and Treatment; MRC: Medical Research Council; RR: risk ratio; SD: standard deviation

GRADE Working Group grades of evidence

High quality: Further research is very unlikely to change our confidence in the estimate of effect.

Moderate quality: Further research is likely to have an important impact on our confidence in the estimate of effect and may change the estimate.

Low quality: Further research is very likely to have an important impact on our confidence in the estimate of effect and is likely to change the estimate.

Very low quality: We are very uncertain about the estimate.

1Downgraded by one, for imprecision. The data are from a single study, which did not achieve planned recruitment, had a small sample size and $95 \% \mathrm{Cl}$ are wide.

2Downgraded twice, for imprecision and indirectness. The data are from a single study, which did not achieve planned recruitment, had a small sample size and $95 \% \mathrm{Cl}$ are wide. The INCAT score is not a linear scale.

${ }^{3}$ Downgraded twice, for imprecision and indirectness. The data are from a single study, which did not achieve planned recruitment, had a small sample size and $95 \% \mathrm{Cl}$ are wide; also, the MRC sum is not a linear scale. 
The endpoint was 12 months or premature cessation of treatment if after 8 weeks if there had been worsening or no stabilisation, or if there was a relapse back to baseline state, or if there were serious side-effects due to the drug.

${ }^{5}$ Downgraded by one for imprecision. The data are from a single study, which did not achieve planned recruitment, had a small sample size and $95 \% \mathrm{Cl}$ are wide (imprecision).

ip strength is a linear and direct measure so we did not downgraded a second time.

${ }^{6}$ Downgraded twice, for serious imprecision and indirectness. The data are from a single study, which did not achieve planned recruitment, had a small sample size and $95 \% \mathrm{C}$ are wide. Sleeplessness is a subjective outcome caused by many factors.

7Downgraded by one for imprecision. The data are from a single study, which did not achieve planned recruitment, had a small sample size and $95 \% \mathrm{Cl}$ are wide. 


\section{B A C K G R O U N D}

\section{Description of the condition}

Chronic inflammatory demyelinating polyradiculoneuropathy (CIDP) is characterised by chronic progressive or relapsing weakness and numbness, especially of the limbs. It affects motor and sensory nerve fibres, but may present with predominantly motor or sensory symptoms. The cerebrospinal fluid (CSF) protein concentration is usually increased. The aetiology of CIDP is presumed to be autoimmune (Hughes 2006; Mathey 2015; Vallat 2010). Biopsy and autopsy studies of active lesions in the peripheral nerves and spinal roots show oedema, lymphocytic infiltration, and macrophage-associated segmental demyelination.

The disease is uncommon. It affects males and females of all ages but is more common in the elderly. Estimates of prevalence range from 2 to 9 per 100,000. Prevalences of 2.84 per 100,000 in England (Mahdi-Rogers 2014) and 3.58 per 100,000 in North Italy are typical (Chiò 2007). In the English study, $32 \%$ of people with CIDP required aid to walk on the prevalence date.

Early, large case series described the clinical picture, but did not precisely define the disease (Barohn 1989; Dyck 1975; McCombe 1987; Prineas 1976). Research criteria for the diagnosis were proposed by the Ad Hoc Subcommittee of the American Academy of Neurology Acquired Immunodeficiency Disease (AIDS) Task Force (AAN 1991). These required fulfilment of clinical and electrophysiological criteria for a diagnosis of "probable" CIDP, and fulfilment of pathological criteria for a diagnosis of "definite" CIDP in which the progressive phase lasted more than eight weeks. These criteria have been extensively debated. More liberal criteria have been widely adopted, including in this review (Van den Bergh 2010).

In this review we relied on the authors' diagnosis of CIDP provided that it fulfilled the spirit of the definition of "probable" CIDP proposed by the Ad Hoc Subcommittee (AAN 1991). Apart from the neurophysiological evidence of multifocal demyelination, there are no reliable diagnostic tests for CIDP, and the diagnosis is, in part, one of exclusion. Differential diagnoses include hereditary, metabolic, vasculitic, amyloid, paraneoplastic, and paraproteinaemic neuropathies. There is a debate about whether some cases of neuropathy associated with diabetes mellitus, systemic lupus erythematosus, and monoclonal gammopathy are due to CIDP. Because of the uncertainty, we planned to exclude such cases from this review. We also excluded multifocal motor neuropathy with conduction block, which is generally recognised to be a separate entity and does not respond to corticosteroids (Van Schaik 2010).

\section{Description of the intervention}

Treatments for CIDP are aimed at suppressing an abnormal autoimmune response. Corticosteroids are potent immunosuppressants. Two commonly used corticosteroids are prednisone and prednisolone. Both are usually given as oral tablets. Prednisone is converted into prednisolone in the liver so that the effect of the two drugs is usually the same. Another corticosteroid, called dexamethasone, is more potent and is used in smaller doses.

Austin 1958 reported dramatic improvement with corticosteroids and relapse following withdrawal, even when the withdrawal was done under blind conditions. From then onwards, corticosteroids were extensively used for CIDP, although only one randomised trial comparing corticosteroids with controls was ever done (Dyck 1982). Subsequently, large retrospective studies on CIDP reported significant improvement after corticosteroids (Barohn 1989; Cocito 2010; Kuwabara 2006; McCombe 1987). The usual regimen has been long-term oral prednisone or prednisolone, with the dose titrated according to the individual's response. Alternative regimens of pulsed high-dose intravenous or oral corticosteroids have been tried, and pulsed high-dose oral dexamethasone has been compared with standard-dose oral prednisolone in the PREDICT 2010 trial.

Although corticosteroids were the first treatment to be used in CIDP, plasma exchange and intravenous immunoglobulin (IVIg) have since been used in randomised controlled trials (RCTs) and shown in Cochrane reviews to be efficacious short-term treatments (Eftimov 2013; Mehndiratta 2015). Limited studies have suggested that plasma exchange is not significantly different from IVIg in efficacy (Dyck 1994), and that IVIg is not significantly different from oral prednisolone (Hughes 2001). A six-month trial found no significant difference in the outcomes between IVIg and intravenous methylprednisolone (Nobile-Orazio 2012). These two trials are included in the Cochrane review of IVIg for CIDP (Eftimov 2013). Many different immunosuppressive agents have been tried and reported in case studies and case series; azathioprine, methotrexate, and beta-interferon have been tested in small RCTs, but none have been shown to be efficacious (MahdiRogers 2010).

\section{How the intervention might work}

Corticosteroids are widely used in medicine as anti-inflammatory agents. They are lipid soluble so that they can easily cross the cell membrane and engage the glucocorticoid receptor in the cytoplasm. The corticosteroid-receptor complex translocates to the nucleus and modifies the transcription of genes, resulting in inhibition of inflammatory mediator release, increase of anti-inflammatory molecules and reduction of circulating Tlymphocytes. In high doses there are also more rapidly acting non-genomic effects on membrane lipids and cytoplasmic proteins which also have an anti-inflammatory effect (Strehl 2013).

\section{Why it is important to do this review}

In view of the lack of evidence of efficacy for cytotoxic and immunomodulatory drugs in CIDP, and the expense and inconvenience of IVIg and plasma exchange, it is important to know the strength of the evidence for corticosteroids, which are commonly recommended as first line treatment. This is an update of a review first published in 2001; the previous update was in 2015.

\section{O B JECTIVES}

To assess the effects of corticosteroid treatment for CIDP compared to placebo or no treatment, and to compare the efficacy of different corticosteroid regimens.

\section{METHODS}

\section{Criteria for considering studies for this review}

\section{Types of studies}

We searched for all RCTs or quasi-RCTs involving any form of corticosteroid or adrenocorticotrophic hormone for the treatment 
of CIDP. Quasi-RCTs are studies in which treatment allocation is organised in a way which is intended to have the effect of randomisation but which might nevertheless be biased (e.g. alternate allocation).

\section{Types of participants}

We included trials in which the study authors had diagnosed participants as having CIDP according to the probable or definite criteria of the European Federation of Neurological Societies/Peripheral Nerve Society (EFNS/PNS) (Van den Bergh 2010). Participants must have had symptoms and signs of peripheral neuropathy characterised by progressive or relapsing motor and sensory dysfunction of more than one limb, and of more than eight weeks' duration. An electrophysiological diagnosis of demyelinating neuropathy based on reduced nerve conduction velocities or partial conduction blocks must have confirmed the clinical diagnosis. The diagnosis might have been confirmed by finding a raised cerebrospinal fluid (CSF) protein or the demonstration of inflammation and macrophage-associated demyelination in a nerve biopsy, but we did not consider these mandatory. We excluded participants with clinical features or investigations suggestive of hereditary neuropathy, relevant systemic disease, or paraproteinaemia.

\section{Types of interventions}

We included treatment with any form of corticosteroid or adrenocorticotrophic hormone compared with either placebo or no treatment, and comparisons of different corticosteroid regimens. We did not include comparisons of corticosteroids with other treatments.

\section{Types of outcome measures}

\section{Primary outcomes}

Change in disability, measured by a validated scale such as the Inflammatory Neuropathy Cause and Treatment (INCAT) disability scale (Hughes 2001), Overall Disability Status Scale (ODSS) (Merkies 2002), Overall Neuropathy Limitations Scale (ONLS) (Graham 2006) or Rasch-built Overall Disability Scale (R-ODS) (Van Nes 2011) after one year.

\section{Secondary outcomes}

1. Change in impairment after three months and one year, measured by a validated scale such as the Mayo Neuropathy Impairment Scale (NIS) (Dyck 1980), Medical Research Council (MRC) Sum Score (Merkies 2006), or grip strength (Merkies 2000).

2. Side effects of corticosteroids for as long as data allowed. We intended to record all reported side effects, including development of diabetes mellitus, infection requiring the use of antibiotics, hypertension requiring treatment, hip fracture, peptic ulcer, gastrointestinal haemorrhage, depression, psychosis, cataract, and change in appearance (hair loss, facial hirsutism, weight loss, and weight redistribution).

\section{Search methods for identification of studies}

\section{Electronic searches}

We modified the search strategy for this update to make it more specific. On 8 November 2016, we searched the Cochrane Neuromuscular Specialised Register, Cochrane Central Register of Controlled Trials (CENTRAL, 8 November 2016 in the Cochrane Register of Studies Online), MEDLINE (January 1966 to November 2016), and Embase (January 1980 to November 2016). See Appendix 1 (Cochrane Neuromuscular Specialised Register), Appendix 2 (CENTRAL), Appendix 3 (MEDLINE), and Appendix 4 (Embase).

\section{Searching other resources}

We also consulted disease experts and on 28 November 2016 searched US National Institutes of Health Ongoing Trials Register ClinicalTrials.gov (www.clinicaltrials.gov), World Health Organization International Clinical Trials Registry Platform (ICTRP) (www.who.int/ictrp/en/) (Appendix 5), and references in reviews and case series of CIDP.

\section{Data collection and analysis}

Two review authors (RACH and MMM) checked titles and abstracts identified in the literature searches. We obtained the full text of potentially includable studies for independent assessment by both authors. Two authors (RACH and MMM) assessed risk of bias according to the method proposed in the Cochrane Handbook for Systematic Reviews of Interventions (Higgins 2011).

We reported dichotomous data as a risk ratio (RR) and continuous data as a mean difference (MD), each with corresponding 95\% confidence intervals $(\mathrm{Cl})$.

If we had found more than one trial investigating a particular intervention, we would have calculated a weighted treatment effect (initially using a fixed-effect model) across trials using the Cochrane statistical package, Review Manager 5 (RevMan 2014).

\section{RE S U L T S}

\section{Description of studies}

\section{Results of the search}

We found 30 ( 3 new) potentially relevant references in the Cochrane Neuromuscular Specialised Register, 29 (8 new) in CENTRAL, 238 (22 new) in MEDLINE and 168 (20 new) in Embase. Of the 55 new references, 7 were already listed in the previous version of the review and the Information Specialist removed 13 by deduplication (Figure 1). None of the remaining 35 references were RCTs eligible for inclusion. Figure 2 is a PRISMA flow chart illustrating the study selection process. 
Figure 1. Study flow diagram.

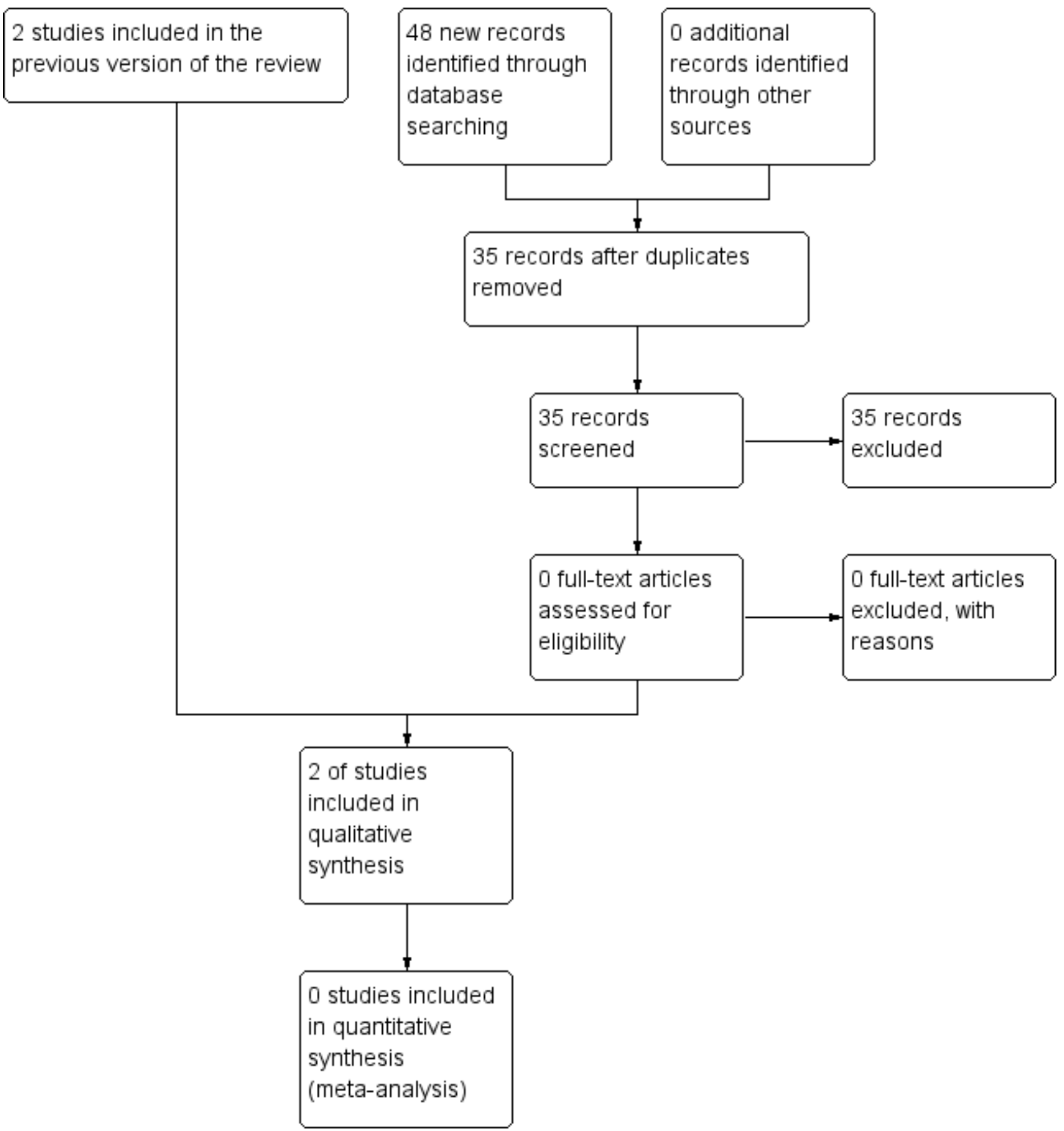


Figure 2. 'Risk of bias' summary: review authors' judgements about each 'Risk of bias' item for each included study. $\operatorname{Red}(-)=$ high risk of bias; green $(-)=$ low risk of bias; yellow (?) (not shown) = unclear risk of bias.

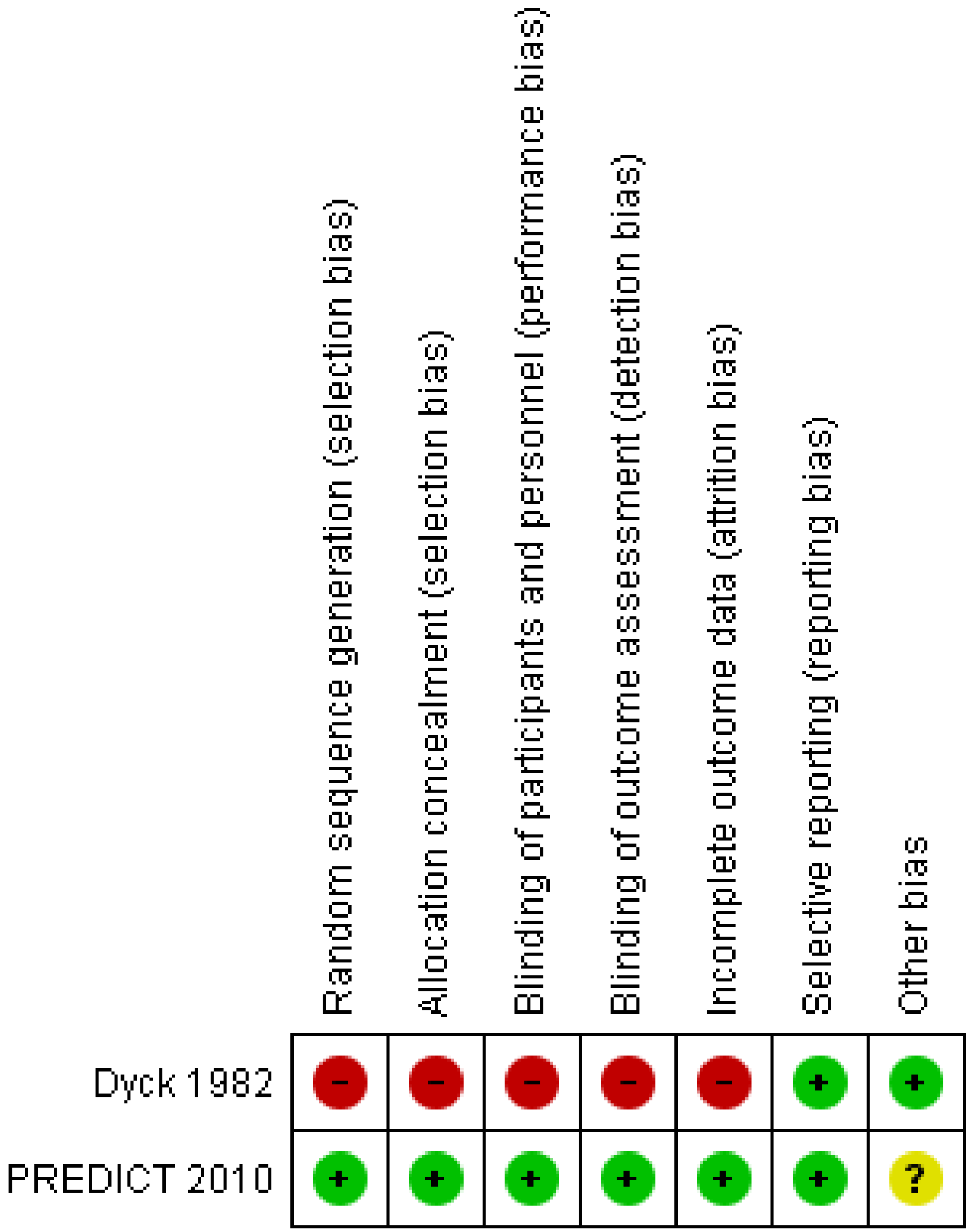

The results of the searches of DARE (one paper), NHSEED (two papers) and HTA database (one paper), produced no additional

relevant references and there were none in ClinicalTrials.gov or 
ICTRP. We found no additional RCTs in the bibliographies of reviews but we have included some additional case series in the Discussion.

\section{Included studies}

Only two studies fulfilled the criteria for this review, one comparing corticosteroids with placebo or no treatment (Dyck 1982), and another comparing two different corticosteroid regimens (PREDICT 2010). An additional trial comparing intravenous methylprednisolone with intravenous immunoglobulin (NobileOrazio 2012) did not fulfil the inclusion criteria for this review and has been considered in another Cochrane Review (Eftimov 2013).

\section{Comparison of oral prednisone with no treatment}

Dyck 1982 compared corticosteroids to no treatment, but did not compare corticosteroids to placebo. The trial recruited 40 participants over 58 months, and assigned them alternately to prednisone or no treatment. Five participants were removed (three in the treated group, and two from the control group) because of misdiagnosis. A further seven (five in the treatment group, and two in the control group) did not complete the study. Of the five assigned to prednisone and excluded, one died from cardiac arrhythmia, possibly related to hyperglycaemia, three had their prednisone dosage altered from that allowed by the schedule, and one remained dependent on a respirator and did not complete follow-up. Two participants in the control group worsened and were started on prednisone by their referring physicians because of deterioration in their neurological status. Of the 28 participants completing the trial, 14 participants belonged to each group (see Characteristics of included studies). The treatment group started on prednisone at a dosage of $120 \mathrm{mg}$ every other day, tapered to $0 \mathrm{mg}$ by the end of 12 weeks. The participants in the two groups were well matched for age, sex, initial neurology disability score, muscle strength, cutaneous sensation, nerve conduction values, and CSF protein. The prednisone group included seven participants with a progressive course and seven with a recurrent course. The untreated group comprised 12 participants with a progressive course and two with a recurrent course.

\section{Comparison of high-dose monthly oral dexamethasone with standard-dose daily oral prednisolone}

One parallel group, double-blind RCT with 41 participants compared two different oral corticosteroid regimens (PREDICT 2010) (see Characteristics of included studies). One group received six cycles of dexamethasone $40 \mathrm{mg}$ daily for four days, followed by placebo for 24 days. The other group received prednisolone for 32 weeks, starting with $60 \mathrm{mg}$ daily for five weeks and then gradually tapering to zero by the 32 nd week.

\section{Risk of bias in included studies}

\section{Comparison of oral prednisone with no treatment}

In Dyck 1982, treatment allocation was randomised for the first person in each pair of participants, but the second person received the alternative treatment, which was supportive care without steroids. There was no placebo, so randomisation was not concealed from the participant. The report does not state whether allocation was concealed from the investigator, or whether follow-up assessments were blinded. The numbers of participants randomised, withdrawn, and not completing treatment were available and the analysis took into account baseline characteristics. In view of the lack of allocation concealment and blinding, we considered this trial to have a high risk of bias (See Characteristics of included studies; Figure 2).

\section{Comparison of high-dose monthly oral dexamethasone with standard-dose daily oral prednisolone}

PREDICT 2010 had a low risk of bias since randomisation was performed, allocation was carefully concealed, and trial medication was identical in appearance in both groups (Characteristics of included studies; Figure 2).

\section{Effects of interventions}

See: Summary of findings for the main comparison Prednisone for chronic inflammatory demyelinating polyradiculoneuropathy; Summary of findings 2 Monthly pulsed high-dose dexamethasone compared to oral prednisolone for chronic inflammatory demyelinating polyradiculoneuropathy

\section{Comparison of oral prednisone with no treatment}

Data for our primary outcome measure, change in disability, were not available for this comparison, but the trial provided data for our secondary outcome measure, change in impairment after three months. In their own analysis, the authors of Dyck 1982 omitted seven participants who breached their protocol, and reported the results for the remainder. The median score at baseline was 74 NIS points in both groups, with the lowest values being 28 , and the highest 137. A healthy person would score zero, with higher values indicating more impairment, with the worst possible score being 280 (the scale is non-linear). After 12 weeks, there was a median deterioration in the NIS score of 1.5 points in the untreated group and an improvement in the prednisone group of 10 points, giving a significant result $(P=0.016)$ (data directly from paper). We were concerned that omission of the seven participants biased the results in favour of prednisone treatment. We repeated their calculations, including the participants who breached protocol and had been excluded, so as to perform a true intention-to-treat (ITT) analysis. When we imputed the worst value for each group for the missing values, the results still favoured prednisone treatment (median increase (worsening) of two points in the control, and decrease (improvement) of five points in the prednisone group), but the difference was not statistically significant. We also calculated the mean improvement in impairment and $95 \% \mathrm{Cl}$ when the seven withdrawn participants were excluded, leaving 28 participants (MD 17.14, 95\% Cl-4.39 to 38.67 ), or when they were included with the assumption that they had not improved (MD $11.60,95 \% \mathrm{Cl}-9.39$ to 32.58 ) (Analysis 1.1; Analysis 1.2; Summary of findings for the main comparison). Although both effect estimates suggested that prednisone may be of clinical benefit, we consider the effects uncertain because vulnerable to the effects of missing data, other risks of bias, and imprecision, with wide $\mathrm{Cl}$ that encompassed benefit and potential harm; the evidence was very low quality.

An alternative method of looking at this outcome, albeit not one which we had stipulated in our protocol, was to compare the proportions of participants who had improved, stayed the same, or worsened after 12 weeks. When this analysis was done omitting the seven participants who breached protocol (i.e. in 28 participants), five participants showed spontaneous improvement, one remained the same, and eight worsened in the control group. On the other hand, in the treatment group, 12 participants improved from their initial impairment score, while two worsened. These 
proportions favoured prednisone (RR $2.40,95 \% \mathrm{Cl} 1.15$ to 5.00 very low-quality evidence; Analysis 1.3; Summary of findings for the main comparison). When we repeated this analysis on all 35 participants, categorising the seven who were withdrawn as not having improved, the result still favoured prednisone, but the effect was slightly smaller and the lower $\mathrm{Cl}$ encompassed the possibility of no effect; the RR for improvement was 2.02 (95\% Cl 0.90 to 4.52; very low-quality evidence; Analysis 1.4; Summary of findings for the main comparison). Other measures of impairment reported by the investigators in the 28 participants who were followed up: touchpressure threshold on the hand $(P=0.017)$ and grip strength $(P=$ 0.046 ), showed significantly more improvement in the prednisonetreated group than the untreated group. These measures were not available for those who were withdrawn and so an ITT analysis was not possible.

The only reported side effect related to treatment was the occurrence of hyperglycaemia in one participant treated with prednisone who was withdrawn.

\section{Outcomes reported but not included in our predefined outcome measures}

Data were also available for electrophysiological outcome measures. Amplitudes, conduction velocities, and latencies of motor fibres of ulnar, median, and peroneal nerves as well as amplitudes and distal latencies of digital nerve action potentials of the median and ulnar nerves were obtained at onset and at three months. The following variables showed significant improvement in the prednisone compared to the control group: median $(\mathrm{P}=$ 0.029) and peroneal $(P=0.056)$ motor nerve conduction velocity and median nerve compound muscle action potential amplitude $(P$ $=0.056$ ). The data on these parameters were not available for those participants who did not complete the protocol.

\section{Comparison of high-dose monthly oral dexamethasone with standard-dose daily oral prednisolone}

PREDICT 2010 did not report the outcomes preselected for this review, but did report meaningful outcomes. The primary outcome defined by the trial authors was reaching and remaining in remission without treatment at 12 months. Remission was defined as a minimum of three points improvement on the RMI and minimum of one point improvement in the INCAT disability scale. If a participant did not show improvement or disease stabilisation compared with baseline at eight weeks, or relapsed or had serious side effects, trial treatment was stopped and this was considered a treatment failure.

Forty-one people were randomly assigned. After one day of trial assignment, one person, who had not by then received any treatment, withdrew because of rapid progression in disease and change in diagnosis. Twenty-four participants were assigned to dexamethasone and 16 to prednisolone. The dexamethasone and prednisolone groups were well matched at baseline. Eighteen men and six women were randomised to dexamethasone and 10 men and six women to prednisolone. The mean (range) age was 59.9 ( 25.8 to 80.2 ) years in the dexamethasone group and 60.8 ( 25.3 to 87.7 ) years in the prednisolone group. The mean (interquartile range) disease duration was 13.5 (5.3 to 28.5) months in the dexamethasone group and 8.5 (6.0 to 15.0$)$ months in the prednisolone group.
In the analysis of the trial authors' primary outcome, 10 out of 24 in the dexamethasone group and six out of 16 in the prednisolone group achieved remission at the end of one year, a difference slightly in favour of dexamethasone, but with wide $\mathrm{Cl}$ that included the possibility of clinically relevant differences in either direction (RR 1.11; $95 \% \mathrm{Cl} 0.50$ to 2.45; moderate-quality evidence; Analysis 2.1; Summary of findings 2). Seven of 24 participants in the dexamethasone and eight of 16 participants in the prednisolone group deteriorated. There were no significant differences between the groups in any of the secondary outcomes measured by the authors, including change at endpoint in MRC sum score (Analysis 2.3; low-quality evidence), grip strength (Analysis 2.4; moderatequality evidence), disability scale, INCAT sensory sum score (lowquality evidence), or Short Form-36 Health Survey quality of life scores. The endpoint was 12 months or premature cessation of treatment if after eight weeks if there had been worsening or no stabilisation, or if there was a relapse back to baseline state, or if there were serious side-effects due to the drug. There was a suggestion that improvement was faster in the dexamethasone treated group; median time to remission was 20 weeks $(95 \% \mathrm{Cl} 12.4$ to 27.6) in the dexamethasone group in comparison to 39 weeks $(95 \% \mathrm{Cl} 29.9$ to 48.1$)$ in the prednisolone group $(\mathrm{P}=0.057)$. Median time to improvement by one point in the INCAT disability scale was 17 weeks $(95 \% \mathrm{Cl} 13.8$ to 20.2$)$ in the dexamethasone group and 39 weeks (29.9 to 48.1$)$ in the prednisolone group $(P=0.036)$.

Side effects, including diabetes mellitus, hypertension, and osteopenia, were comparably common in both groups, with the exception of sleeplessness and cushingoid facies, which were more common in the daily prednisolone group (RR $0.44,0.24$ to 0.84 and RR $0.50,0.21$ to 1.17 , respectively; low- and moderate-quality evidence) (Analysis 2.5; Analysis 2.6; Summary of findings 2). Severe weight gain (> $3 \mathrm{~kg}$ ) was more common with daily prednisolone than with dexamathasone ( $\mathrm{RR} 0.11,95 \% \mathrm{Cl} 0.01$ to 0.84 ) but weight gain of $1 \mathrm{~kg}$ to $3 \mathrm{~kg}$ was not, although this result was somewhat imprecise (RR $0.96,95 \% \mathrm{Cl} 0.55$ to 1.70 ) (Analysis 2.7; Analysis 2.8). One participant in the dexamethasone group developed acute glaucoma after one cycle and stopped treatment.

\section{DISCUSSION}

\section{Comparison of corticosteroids with no treatment}

\section{Summary of the main results and quality of the evidence}

The Dyck 1982 trial comparing prednisone for 12 weeks with no treatment was a pioneering study in the field of inflammatory neuropathy. By modern standards the trial had a high risk of bias because of failure to conceal allocation, absence of blinding, and lack of ITT analysis. Additionally, the sample size was small, the outcome measures non-linear and compound, and the result imprecise. The trial authors concluded that corticosteroids significantly reduced impairment and improved measures of nerve conduction. There was no information concerning disability, our preferred primary outcome measure. When we imputed pessimistic values for the participants who were withdrawn and reanalysed, the results for one of our secondary outcome measures, improvement in impairment 12 weeks after randomisation, favoured corticosteroids, but the quality of evidence was very low (Summary of findings for the main comparison). The interpretation of the results of the trial is critically dependent on how the withdrawn participants are analysed. One withdrawn prednisone participant died and another remained ventilated, which favours 
no prednisone. Two withdrawn control participants worsened and then improved on prednisone, which favours prednisone. In the study authors' own analysis, excluding the seven participants who breached protocol, there was significant improvement in measures of sensory threshold, grip strength and nerve conduction. The absence of a true ITT analysis seriously weakens the strength of the evidence that corticosteroids are beneficial.

\section{Overall completeness and applicability of the evidence}

There have been no trials comparing corticosteroids with placebo in CIDP. Since there is so little evidence from randomised studies, we also considered large series in which the use of corticosteroids has been reported. In 1958, Austin described recurrent steroidresponsiveness in two people and reviewed nine others (Austin 1958). In one, Austin demonstrated steroid-responsiveness through documentation of 20 recurrences over a five-year period compared with significant progression following oral, intramuscular, and intravenous placebo administration. Others reported benefit from corticosteroids in single cases or small case series (DeVivo 1970; Thomas 1969).

Dalakas 1981 reported 25 people with CIDP treated with corticosteroids alone in an observational study in which "the majority" improved. The study authors emphasised that a lag period, usually of one to four weeks, but occasionally up to five months, occurred from onset of therapy to the first sign of improvement. They recommended high doses of steroids for about one year, then cautious tapering to avoid pharmacorelapses, and long-term, low, maintenance doses to prevent spontaneous relapses. Beneficial effects of corticosteroids have also been documented in children with CIDP (Hattori 1998; Nevo 1996; Simmons 1997; Sladky 1986).

McCombe 1987 reported a study of 92 cases of all ages. Sixty (65\%) participants had a relapsing course and 32 participants (35\%) a progressive or monophasic course. Seventy-six participants were treated with corticosteroids. Forty-nine participants (65\%) made a good recovery and were independent. Similarly, Barohn 1989 studied 60 people aged 10 to 77 years. A consistent approach to treatment was used over the decade of observation. Participants were started on a regimen of $100 \mathrm{mg}$ of prednisone daily for two to four weeks and then switched to prednisone $100 \mathrm{mg}$ in a single dose on alternate days. This regimen was continued until clinical improvement plateaued. If the participant's response was poor or a relapse occurred, either azathioprine or plasma exchange was added to the treatment. Fifty-six (94.9\%) of 59 treated participants showed initial improvement with immunosuppressive treatment. The mean (standard deviation (SD)) time for improvement was 1.9 (3.6) months. The mean time to reach a clinical plateau was 6.6 (5.4) months. In an abstract, Machkhas 1997 reported benefit from pulsed intravenous methylprednisolone $1000 \mathrm{mg}$ daily for five days and then $1000 \mathrm{mg}$ daily every one to four weeks in five people with CIDP. Side effects were not reported. Sabatelli 2001 reported that four people with pure motor CIDP did not respond to prednisolone but all four responded to IVIg. Particularly helpful is the detailed, albeit retrospective, Italian national study which included 136 people with CIDP treated with corticosteroids as first line therapy, of whom $51 \%$ responded with a one or more point improvement in the Rankin score and 19 of whom (12.5\%) had side effects (five people with diabetes mellitus, four with hypertension, three with osteoporosis, three with duodenal ulcer, two with psychosis, and one with obesity) (Cocito 2010). Fourteen participants who had previously been treated with IVIg were switched to corticosteroids, and six (43\%) responded. This large systematic national survey suggests that corticosteroids induce at least short-term improvement in about half of people with CIDP, less than the $65 \%$ or more suggested by smaller case series studies from single centres. It also documents the improvement of some people on corticosteroids after switching from IVIg, which has been noted before (Pedersen 2007).

Care must be exercised in starting treatment because some people with CIDP deteriorate, as reported in case series (Dyck 1975; Rostasy 2003) and PREDICT 2010. In a post hoc analysis of PREDICT 2010, seven of 33 participants deteriorated within eight weeks after start of treatment, four patients had received dexamethasone and three had received prednisolone (Eftimov 2014).

There is no known method for identifying people with CIDP who will deteriorate. Deterioration has been considered more likely in pure motor CIDP (Donaghy 1994), but also occurs in pure sensory CIDP (Chroni 2015; Rajabally 2012). The likelihood of response to steroids in various atypical forms of CIDP is also uncertain. A retrospective review of published accounts of multifocal asymmetric upper limb-onset CIDP found that $52 \%$ of people (14 of 27) treated with steroids improved compared to $74 \%$ (31 of 42 ) of those treated with IVIg. The same review found that people with multifocal asymmetric lower limb-onset forms were significantly less likely to respond to steroids than IVIg (2 of $8(25 \%)$ versus 14 of $16(87 \%)$ ) (Rajabally 2009). According to a retrospective study of seven people with corticosteroid-responsive disease and seven who were non-responsive to corticosteroid, corticosteroid response was significantly more likely in those with smaller sensory action potentials and longer upper limb F wave latencies (Rajabally 2008). In a retrospective study of 50 people with CIDP (Chan 2006), there was no difference in responsiveness to any immunotherapy (including IVIg, as well as corticosteroids) between 27 people with neurophysiologically definite and 23 people with neurophysiologically probable CIDP, classified according to the INCAT criteria (Hughes 2001). Five out of seven people with early deterioration had a focal distribution pattern of demyelination, compared to only five out of 26 people without early deterioration $(P=0.02)$ (Eftimov 2014). This observation suggests that a focal pattern of demyelination might predict worsening after starting corticosteroids. but this requires confirmation in new prospective studies. The mechanism by which corticosteroids can cause worsening is not known. Eftimov 2014 speculated that corticosteroids might upregulate the axonal $\mathrm{Na}+\mathrm{K}+$ pump, causing hyperpolarisation and conduction block, especially in motor nerve fibres.

The issue of side effects is very important in deciding whether to use corticosteroids as the first line treatment for CIDP (Bromberg 2004). Side effects include weight gain, hirsutism, cushingoid or moon facies, susceptibility to overwhelming infection, osteoporosis, hip fracture, hypertension, diabetes mellitus, cataracts, peptic ulcer, gastrointestinal haemorrhage, and psychiatric manifestations (Goodman 1996), many of which have been reported in the case series studies described in the discussion above. Many of these effects are not adequately captured in short-term trials, even those with follow-up for one year, but are relevant when considering the value of long-term treatment.

Cost is another important consideration. Oral prednisone or prednisolone are cheap to purchase but monitoring for the known 
side effects incurs costs, and the long-term costs of serious side effects are substantial. However, even when these are taken into account, corticosteroids are much less expensive than the main alternative, IVIg (Blackhouse 2010; McCrone 2003).

\section{Comparison of different corticosteroid regimens}

\section{Summary of the main results and quality of the evidence}

One trial compared a commonly-used regimen of standarddose daily oral prednisolone with monthly, high-dose, oral dexamethasone (PREDICT 2010). There was probably little or no difference between regimens in the primary outcome chosen by the trial authors (remission after 12 months). Monthly dexamethasone produced a more rapid one point INCAT improvement than oral prednisolone, which reached statistical significance. Unexpectedly, one-third of the participants deteriorated, slightly but not significantly more in the daily prednisolone group. Minor side effects were common, and sleeplessness (low-quality evidence) and cushingoid facies (moderate-quality evidence) were more common in the prednisolone group. Weight gain of more than $3 \mathrm{~kg}$ was more common in the prednisolone group both during treatment and follow-up periods. The trial had a low risk of bias. The limitations of this evidence, which we judged to be of low to moderate quality for efficacy, are that there was only one trial, the sample size was smaller than intended because of the slow recruitment rate, and some measures were imprecise and also to an extent indirect (Summary of findings 2).

The trial included an informal follow-up after a median 4.5 years when data were available from 39 of 40 participants (Eftimov 2011; Eftimov 2012). Cure (off treatment $>$ five years) or remission (off treatment $>$ five years) occurred in seven out of 24 participants initially treated with pulsed dexamethasone and six out of 16 participants initially treated with prednisolone. Half those in remission after initial treatment relapsed. The median treatmentfree interval was longer, 17.5 months, for pulsed dexamethasone than for conventional dose prednisolone (11 months), which was not a clear difference. Unfortunately, the different treatments received after the end of the one-year trial confounded these comparisons. Importantly, the diagnosis turned out to be wrong in seven participants, who accounted for more than half of the 12 who did not respond to any treatment.

\section{Overall completeness and applicability of the evidence}

There have been many case reports, case series studies, and reviews describing widely varying types, doses and routes of corticosteroid usage in CIDP (Bromberg 2004), but no other RCTs. PREDICT 2010 was based on an observational study of six cycles of oral dexamethasone $40 \mathrm{mg}$ daily for four days every four weeks, in which six of ten participants went into remission (Molenaar 1997). A retrospective observational study of 39 participants (out of 57 with available records), included 16 participants who received intermittent intravenous methylprednisolone $1000 \mathrm{mg}$ daily for three to five days and then $1000 \mathrm{mg}$ monthly, seven who received $\mathrm{IVIg}$, and 16 people who received oral treatment consisting of either prednisone (in 12) or ciclosporin (in four) (Lopate 2005). After six months, the average improvement in muscle strength was similar in all three groups. Cushingoid appearance and weight gain were more common in those who received oral prednisone. Kuwabara 2006 treated 38 people with CIDP of whom 33 received high-dose corticosteroids as their first treatment: of these $33,70 \%$ improved by one or more points on the seven-point GBS disability grade scale by two months. Some people were subsequently treated with IVIg or plasma exchange so that their five-year status cannot be attributed solely to corticosteroids, but $26 \%$ were in complete remission off treatment, $29 \%$ were still being treated with corticosteroids, $10 \%$ needed aid to walk, and one had died of complications associated with tetraplegia. Side effects were not mentioned. In another retrospective observational study, Muley 2008 treated 10 people with oral methylprednisolone $500 \mathrm{mg}$ once a week for three months, and the dose was adjusted every three months by $50 \mathrm{mg}$ to $100 \mathrm{mg}$ depending on clinical status. One person stopped treatment after two days because of duodenal ulceration, but six of the remaining nine entered and maintained treatment-free remission after a mean of 27 (SD 7.04) months. Longterm skin thinning and cushingoid facies were each reported in three people, and five people developed osteoporosis.

Boru 2014 treated 20 people with CIDP with intravenous methylprednisolone $1000 \mathrm{mg} /$ day for 10 days and then $1000 \mathrm{mg}$ monthly for five years. Five people were not followed up, one because of lack of response, another because of nausea and hypertension, and three for reasons unrelated to the study. The remaining 15 all improved compared with baseline by at least one point on the modified Rankin score at the first and fifth year. After five years, treatment was stopped and during a five further years' follow-up, six participants relapsed. All those relapsing received intravenous methylprednisolone again and three responded. Sideeffects occurred in nearly half the participants, including weight gain in six, but no other participants had to stop treatment.

The inclusion criteria for this review did not allow us to consider RCTs comparing corticosteroids with IVIg or other treatments (Hughes 2001; Nobile-Orazio 2012). These have been considered in the Eftimov 2013 Cochrane review and the Oaklander 2017 Cochrane overview.

\section{Comparison of corticosteroids with no treatment and comparison of different corticosteroid regimens}

\section{Potential biases in the review process}

For both the comparisons included in this review, we are confident that we have identified all RCTs comparing corticosteroids with placebo or no treatment and comparing different corticosteroid regimens. However, the exclusion of comparisons with other treatments especially IVIg is a limitation which has been corrected by their inclusion in other reviews (Eftimov 2013; Oaklander 2017). We also recognise that it is not possible to identify all the nonrandomised evidence. Our review of published case series may not be complete, and will have been limited by the impossibility of including all treated and untreated people with CIDP. Of concern is that one of the RCTs identified only considered 12 weeks of treatment, and the other only 12 months, whereas in practice, people with CIDP may require treatment for years. Longer RCTs of corticosteroids are unlikely to be done.

\section{Agreements and disagreements with other studies or reviews}

There have been no other systematic reviews. The conclusions of this review are in line with the assessment of the evidence by an international expert panel (Van den Bergh 2010). A more recent non-systematic review including the comparison of corticosteroids with IVIg supports the use of pulsed high-dose corticosteroids rather than IVIg as the first treatment choice in people with non-motor-dominant CIDP who are not extremely disabled (Press 
2016). Two other Cochrane reviews consider the comparison of corticosteroids with IVIg (Eftimov 2013; Oaklander 2017).

\section{AUTHORS' CONCLUSIONS}

\section{Implications for practice}

We are very uncertain about the effects of prednisone in comparison to no treatment in chronic inflammatory demyelinating polyradiculoneuropathy as the quality of evidence is very low. Nevertheless, corticosteroids are commonly used in practice, supported by very low-quality evidence from observational studies and apparent clinical efficacy in day-today use. Corticosteroids are known from observational studies to carry the long-term risk of serious side effects. High-dose monthly oral dexamethasone probably has similar efficacy to daily oral prednisolone. Both cause short-term side effects, but sleeplessness may be less common and moon facies is probably less common with monthly dexamethasone.

\section{Implications for research}

Further research is needed to identify factors which predict response and deterioration after corticosteroids. Randomised controlled trials are urgently needed to discover whether corticosteroids are cost effective compared with other treatments, especially intravenous immunoglobulin, and whether adjunctive treatment with immunosuppressive agents is superior to corticosteroids alone.

\section{ACKNOWLEDGEMENTS}

The authors thank Mrs Angela Gunn, the Information Specialist at the Cochrane Neuromuscular Editorial base, for designing the search strategy and undertaking the searches.

This project was supported by the National Institute for Health Research (NIHR) via Cochrane Infrastructure funding to Cochrane Neuromuscular. The views and opinions expressed herein are those of the review authors and do not necessarily reflect those of the Systematic Reviews Programme, NIHR, National Health Service, or the Department of Health. Cochrane Neuromuscular is also supported by the MRC Centre for Neuromuscular Diseases. 


\section{RE F E R E N C E S}

\section{References to studies included in this review \\ Dyck 1982 \{published data only\}}

Dyck PJ, O'Brien PC, Oviatt KF, Dinapoli RP, Daube JR, Bartleson JD, et al. Prednisone improves chronic inflammatory polyradiculoneuropathy more than no treatment. Annals of Neurology 1982;11(2):136-41. [PUBMED: 7041788]

\section{PREDICT 2010 \{published data only\}}

Eftimov F, Vermeulen M, Van Doorn PA, Brusse E, Van Schaik IN, PREDICT. Long-term remission of CIDP after pulsed dexamethasone or short-term prednisolone treatment. Neurology 2012;78(14):1079-84.

Van Schaik IN, Eftimov F, Van Doorn PA, Brusse E, Van den Berg LH, Van der Pol WL, et al. Pulsed high-dose dexamethasone versus standard prednisolone treatment for chronic inflammatory demyelinating polyradiculoneuropathy (PREDICT study): a double-blind, randomised, controlled trial. Lancet Neurology 2010;9(3):245-53. [PUBMED: 20133204]

\section{References to studies excluded from this review}

\section{Lopate 2005 \{published data only\}}

Lopate A, Pestronk A, Al-Lozi M. Treatment of chronic inflammatory demyelinating polyneuropathy with high-dose intermittent intravenous methylprednisolone. Archives of Neurology 2005;62(2):249-54.

\section{Nobile-Orazio 2012 \{published data only\}}

* Nobile-Orazio E, Cocito D, Jann S, Uncini A, Beghi E, Messina $P$, et al. Intravenous immunoglobulin versus intravenous methylprednisolone for chronic inflammatory demyelinating polyradiculoneuropathy: a randomised controlled trial. Lancet Neurology 2012;11(6):493-502.

Nobile-Orazio E, Cocito D, Jann S, Uncini A, Messina P, Antonini $\mathrm{G}$, et al. Frequency and time to relapse after discontinuing 6-month therapy with IVIg or pulsed methylprednisolone in CIDP. Journal of Neurology, Neurosurgery \& Psychiatry 2015;86(7):729-34.

Nobile-Orazio E, Cocito D, Jann S, Uncini A, Messina P, Antonini $\mathrm{G}$, et al. Frequency and time to relapse after therapy discontinuation in CIDP patients treated for six months with IVIG or IV methylprednisolone (IMC study follow-up). Journal of the Peripheral Nervous System 2013;18 Suppl:S80-1.

\section{Additional references}

\section{AAN 1991}

American Academy of Neurology. Research criteria for diagnosis of chronic inflammatory demyelinating polyneuropathy (CIDP). Report from an Ad Hoc Subcommittee of the American Academy of Neurology AIDS Task Force. Neurology 1991;41(5):617-8.

\section{Austin 1958}

Austin JH. Recurrent polyneuropathies and their corticosteroid treatment. With five-year observations of a placebo controlled case treated with corticotrophin, cortisone and prednisone. Brain 1958;81(2):157.

\section{Barohn 1989}

Barohn RJ, Kissel JT, Warmolts JR, Mendell JR. Chronic inflammatory demyelinating polyradiculoneuropathy: Clinical characteristics, course, and recommendations for diagnostic criteria. Archives of Neurology 1989;46(8):878-84.

\section{Blackhouse 2010}

Blackhouse G, Gaebel K, Xie F, Campbell K, Assasi N, Tarride JE, et al. Cost-utility of intravenous immunoglobulin (IVIG) compared with corticosteroids for the treatment of chronic inflammatory demyelinating polyneuropathy (CIDP) in Canada. Cost Effectiveness and Resource Allocation 2010;8:14.

\section{Boru 2014}

Börü UT, Erdoğan H, Alp R, Taşdemir M, Yildirim S, Bilgiç A, et al. Treatment of chronic inflammatory demyelinating polyneuropathy with high dose intravenous methylprednisolone monthly for five years: 10-year follow up. Clinical Neurology \& Neurosurgery 2014;118:89-93.

\section{Bromberg 2004}

Bromberg MB, Carter O. Corticosteroid use in the treatment of neuromuscular disorders: empirical and evidence-based data. Muscle \& Nerve 2004;30(1):20-37.

\section{Chan 2006}

Chan YC, Allen DC, Fialho D, Mills KR, Hughes RA. Predicting response to treatment in chronic inflammatory demyelinating polyradiculoneuropathy. Journal of Neurology, Neurosurgery \& Psychiatry 2006;77(1):114-6.

\section{Chiò 2007}

Chiò A, Cocito D, Bottacchi E, Buffa C, Leone M, Plano F, et al. Idiopathic chronic inflammatory demyelinating polyneuropathy: an epidemiological study in Italy. Journal of Neurology, Neurosurgery \& Psychiatry 2007;78(12):1349-53.

\section{Chroni 2015}

Chroni E, Veltsista D, Gavanozi E, Vlachou T, Polychronopoulos P, Papathanasopoulos P. Pure sensory chronic inflammatory polyneuropathy: rapid deterioration after steroid treatment. BMC Neurology 2015;15:27.

\section{Cocito 2010}

Cocito D, Paolasso I, Antonini G, Benedetti L, Briani C, Comi C, et al. A nationwide retrospective analysis on the effect of immune therapies in patients with chronic inflammatory demyelinating polyradiculoneuropathy. European Journal of Neurology 2010;17(2):289-94.

\section{Collen 1991}

Collen FM, Wade DT, Robb GF, Bradshaw CM. The Rivermead Mobility Index: a further development of the Rivermead Motor Assessment. International Disability Studies 1991;13(2):50-4. 


\section{Dalakas 1981}

Dalakas MC, Engel WK. Chronic relapsing (dysimmune) polyneuropathy: pathogenesis and treatment. Annals of Neurology 1981;9 Suppl:134-45.

\section{DeVivo 1970}

DeVivo DC, Engel WK. Remarkable recovery of a steroidresponsive recurrent polyneuropathy. Journal of Neurology, Neurosurgery \& Psychiatry 1970;33(1):62-9.

\section{Donaghy 1994}

Donaghy M, Mills KR, Boniface SJ, Simmons J, Wright I, Gregson N, et al. Pure motor demyelinating neuropathy: Deterioration after steroid treatment and improvement with intravenous immunoglobulin. Journal of Neurology, Neurosurgery \& Psychiatry 1994;57(7):778-83.

\section{Dyck 1975}

Dyck PJ, Lais AC, Ohta M, Bastron JA, Okazaki H, Groover RV. Chronic inflammatory polyradiculoneuropathy. Mayo Clinic Proceedings 1975;50(11):621-37.

\section{Dyck 1980}

Dyck PJ, Sherman WR, Hallcher LM, Service FJ, O'Brien PC, Grina LA, et al. Human diabetic endoneurial sorbitol, fructose and myo-inositol related to sural nerve morphometry. Annals of Neurology 1980;8(6):590-6.

\section{Dyck 1994}

Dyck PJ, Litchy WJ, Kratz KM, Suarez GA, Low PA, Pineda AA, et al. A plasma exchange versus immune globulin infusion trial in chronic inflammatory demyelinating polyradiculoneuropathy. Annals of Neurology 1994;36(6):838-45.

\section{Eftimov 2011}

Eftimov F, Vermeulen M, Van Doorn PA, Brusse E, Van Schaik IN, The PREDICT study group. Long term follow-up in CIDP patients treated with 6-months pulsed dexamethasone or 8-months prednisolone treatment. 2011 Meeting of the Peripheral Nerve Society June 25-29, 2011, Potomac, Maryland. Journal of the Peripheral Nervous System. 2011, issue 16 Suppl s3:S33-4.

\section{Eftimov 2012}

Eftimov F, Vermeulen M, Van Doorn PA, Brusse E, Van Schaik IN, PREDICT. Long-term remission of CIDP after pulsed dexamethasone or short-term prednisolone treatment. Neurology 2012;78(14):1079-84.

\section{Eftimov 2013}

Eftimov F, Winer JB, Vermeulen M, De Haan R, Van Schaik IN. Intravenous immunoglobulin for chronic inflammatory demyelinating polyradiculoneuropathy. Cochrane Database of Systematic Reviews 2013, Issue 12. [DOI: 10.1002/14651858.CD001797.pub3]

\section{Eftimov 2014}

Eftimov F, Liesdek MH, Verhamme C, Van Schaik IN, on behalf of the PREDICT study group. Deterioration after corticosteroids in CIDP may be associated with pure focal demyelination pattern. BMC Neurology 2014;14:72.

\section{Franssen 1997}

Franssen $\mathrm{H}$, Vermeulen M, Jennekens FG. Chronic inflammatory neuropathies. In: Emery AEH editor(s). Diagnostic Criteria for Neuromuscular Disorders. 2nd Edition. London: RSM Press, 1997:53-9.

\section{Goodman 1996}

Bernard PS, Keith LP. Adrenocorticotropic hormones; adrenocortical steroids and their synthetic analogues, inhibitors of the synthesis and action of adrenocortical hormones. In: Joel GH, Lee EL editor(s). Goodman and Gilman. The Pharmacological Basis of Therapeutics. 9th Edition. New York: McGraw Hill, 1996:1459-84.

\section{Graham 2006}

Graham RC, Hughes RA. A modified peripheral neuropathy scale: the Overall Neuropathy Limitations Scale. Journal of Neurology, Neurosurgery \& Psychiatry 2006;77(8):973-6.

\section{Hattori 1998}

Hattori N, Ichimura M, Aoki S, Nagamatsu M, Yasuda T, Kumazawa K, et al. Clinicopathological features of chronic inflammatory demyelinating polyradiculoneuropathy in childhood. Journal of the Neurological Sciences 1998;154(1):66-71.

\section{Higgins 2011}

Higgins JPT, Altman DG, Sterne JAC (editors). Chapter 8: Assessing risk of bias in included studies. In Higgins JPT, Green S (editors). Cochrane Handbook for Systematic Reviews of Interventions Version 5.1.0 (updated March 2011). The Cochrane Collaboration, 2011. Available from www.cochranehandbook.org.

\section{Hughes 2001}

Hughes R, Bensa S, Willison H, Van den Bergh P, Comi G, Illa I, et al. Randomized controlled trial of intravenous immunoglobulin versus oral prednisolone in chronic inflammatory demyelinating polyradiculoneuropathy. Annals of Neurology 2001;50(2):195-201.

\section{Hughes 2006}

Hughes RA, Allen D, Makowska A, Gregson NA. Pathogenesis of chronic inflammatory demyelinating polyradiculoneuropathy. Journal of the Peripheral Nervous System 2006;11(1):30-46.

\section{Kuwabara 2006}

Kuwabara S, Misawa S, Mori M, Tamura N, Kubota M, Hattori T. Long term prognosis of chronic inflammatory demyelinating polyneuropathy: a five year follow up of 38 cases. Journal of Neurology, Neurosurgery \& Psychiatry 2006;77(1):66-70.

\section{Machkhas 1997}

Machkhas $\mathrm{H}$, Harati Y. Pulse intravenous methylprednisolone (IVMP) in the treatment of chronic inflammatory demyelinating polyradiculoneuropathy (CIDP). Neurology 1997; Vol. 48, issue 3 Suppl:A87-8.

\section{Mahdi-Rogers 2010}

Mahdi-Rogers M, Swan AV, Van Doorn PA, Hughes RA. Immunomodulatory treatment other than corticosteroids, 
immunoglobulin and plasma exchange for chronic inflammatory demyelinating polyradiculoneuropathy. Cochrane Database of Systematic Reviews 2013, Issue 6. [DOI: 10.1002/14651858.CD003280.pub4]

\section{Mahdi-Rogers 2014}

Mahdi-Rogers M, Hughes RA. Epidemiology of chronic inflammatory neuropathies in southeast England. European Journal of Neurology 2014;21(1):28-33.

\section{Mathey 2015}

Mathey EK, Park SB, Hughes RA, Pollard JD, Armati PJ, Barnett $\mathrm{MH}$, et al. Chronic inflammatory demyelinating polyradiculoneuropathy: from pathology to phenotype. Journal of Neurology, Neurosurgery \& Psychiatry 2015;86(9):973-85.

\section{McCombe 1987}

McCombe PA, Pollard JD, McLeod JG. Chronic inflammatory demyelinating polyradiculoneuropathy. A clinical and electrophysiological study of 92 cases. Brain 1987;110(Pt 6):1617-30.

\section{McCrone 2003}

McCrone P, Chisholm D, Knapp M, Hughes R, Comi G, Dalakas MC, et al. INCAT Study Group. Cost-utility analysis of intravenous immunoglobulin and prednisolone for chronic inflammatory demyelinating polyradiculoneuropathy. European Journal of Neurology 2003;10(6):687-94.

\section{Mehndiratta 2015}

Mehndiratta MM, Hughes RA, Pritchard J. Plasma exchange for chronic inflammatory demyelinating polyradiculoneuropathy. Cochrane Database of Systematic Reviews 2015, Issue 8. [DOI: 10.1002/14651858.CD003906.pub4]

\section{Merkies 2000}

Merkies ISJ, Schmitz PIM, Samijn JPA, Van der Meché FGA, Toyka KV, Van Doorn PA, et al. Assessing grip strength in healthy individuals and patients with immune-mediated polyneuropathies. Muscle \& Nerve 2000;23(9):1393-401.

\section{Merkies 2002}

Merkies IS, Schmitz PI, Van der Meché FG, Samijn JP, Van Doorn PA. Clinimetric evaluation of a new overall disability scale in immune mediated polyneuropathies. Journal of Neurology, Neurosurgery \& Psychiatry 2002;72(5):596-601.

\section{Merkies 2006}

Merkies IS, Lauria G. 131st ENMC international workshop: selection of outcome measures for peripheral neuropathy clinical trials 10-12 December 2004, Naarden, The Netherlands. Neuromuscular Disorders 2006;16(2):149-56.

\section{Molenaar 1997}

Molenaar DSM, Van Doorn PA, Vermeulen M. Pulsed high dose dexamethasone treatment in chronic inflammatory demyelinating polyneuropathy: a pilot study. Journal of Neurology, Neurosurgery \& Psychiatry 1997;62(4):388-90.

\section{Muley 2008}

Muley SA, Kelkar P, Parry GJ. Treatment of chronic inflammatory demyelinating polyneuropathy with pulsed oral steroids. Archives of Neurology 2008;65(11):1460-4.

\section{Nevo 1996}

Nevo Y, Pestronk A, Kornberg AJ, Connolly AM, Yee WC Iqbal I, et al. Childhood chronic inflammatory demyelinating neuropathies. Neurology 1996;47(1):98-102.

\section{Oaklander 2017}

Oaklander AL, Lunn MPT, Hughes RAC, Van Schaik IN, Frost C, Chalk $\mathrm{CH}$. Treatments for chronic inflammatory demyelinating polyradiculoneuropathy (CIDP): an overview of systematic reviews. Cochrane Database of Systematic Reviews 2017, Issue 1. [DOI: 10.1002/14651858.CD010369.pub2]

\section{Pedersen 2007}

Pedersen K, Pandolfo M, Mavroudakis N. Chronic inflammatory demyelinating polyneuropathy in a diabetic patient: deterioration after intravenous immunoglobulins treatment and favorable response to steroid treatment. Acta Neurologica Belgica 2007;107(1):14-7.

\section{Press 2016}

Press R, Hiew FL, Rajabally YA. Steroids for chronic inflammatory demyelinating polyradiculoneuropathy: evidence base and clinical practice. Acta Neurologica Scandinavica 2016;133(4):228-38.

Prineas 1976

Prineas JW, McLeod JG. Chronic relapsing polyneuritis. Journal of the Neurological Sciences 1976;27(4):427-58.

\section{Rajabally 2008}

Rajabally YA, Narasimhan M, Chavada G. Electrophysiological predictors of steroid-responsiveness in chronic inflammatory demyelinating polyneuropathy. Journal of Neurology 2008;255(6):936-8.

\section{Rajabally 2009}

Rajabally YA, Chavada G. Lewis-Sumner syndrome of pure upper-limb onset: diagnostic, prognostic, and therapeutic features. Muscle \& Nerve 2009;39(2):206-20.

\section{Rajabally 2012}

Rajabally YA, Wong SL. Chronic inflammatory pure sensory polyradiculoneuropathy: a rare CIDP variant with unusual electrophysiology. Journal of Clinical Neuromuscular Disease 2012;13(3):149-52.

\section{RevMan 2014 [Computer program]}

The Nordic Cochrane Centre, The Cochrane Collaboration. Review Manager (RevMan). Version 5.3. Copenhagen: The Nordic Cochrane Centre, The Cochrane Collaboration, 2014.

\section{Rostasy 2003}

Rostasy KM, Diepold K, Buckard J, Brockmann K, Wilken B, Hanefeld F. Progressive muscle weakness after high-dose steroids in two children with CIDP. Pediatric Neurology 2003;29(3):236-8. 


\section{Sabatelli 2001}

Sabatelli M, Madia F, Mignogna T, Lippi G, Quaranta L, Tonali P. Pure motor chronic inflammatory demyelinating polyneuropathy. Journal of Neurology 2001;248(9):772-7.

\section{Simmons 1997}

Simmons Z, Wald JJ, Albers JW. Chronic inflammatory demyelinating polyradiculoneuropathy in children. II. Long term follow-up, with comparison to adults. Muscle \& Nerve 1997;20(12):1569-75.

\section{Sladky 1986}

Sladky JT, Brown MJ, Berman PH. Chronic inflammatory demyelinating polyneuropathy of infancy: a corticosteroid responsive disorder. Annals of Neurology 1986;20(1):76-81.

\section{Strehl 2013}

Strehl C, Buttgereit F. Optimized glucocorticoid therapy: teaching old drugs new tricks. Molecular and Cellular Endocrinology 2013;380(1-2):32-40.

\section{Thomas 1969}

Thomas PK, Lascelles RG, Hallpike JF, Hewer RL. Recurrent and chronic relapsing Guillain-Barre polyneuritis. Brain 1969;92(3):589-606.

\section{Vallat 2010}

Vallat JM, Sommer C, Magy L. Chronic inflammatory demyelinating polyradiculoneuropathy: diagnostic and therapeutic challenges for a treatable condition. Lancet Neurology 2010;9(4):402-12.

\section{Van den Bergh 2010}

Van den Bergh PY, Hadden RD, Bouche P, Cornblath DR, Hahn A, Illa I, et al. European Federation of Neurological Societies/ Peripheral Nerve Society guideline on management of chronic inflammatory demyelinating polyradiculoneuropathy: report of a joint task force of the European Federation of Neurological Societies and the Peripheral Nerve Society - first revision. European Journal of Neurology 2010;17(3):356-63.

\section{Van Nes 2011}

Van Nes SI, Vanhoutte EK, Van Doorn PA, Hermans M, Bakkers M, Kuitwaard K, et al. Rasch-built Overall Disability Scale (R-ODS)

\section{CHARACTERISTICS OF STUDIES}

Characteristics of included studies [ordered by study ID] for immune-mediated peripheral neuropathies. Neurology 2011;76(4):337-45

\section{Van Schaik 2010}

Van Schaik IN, Léger J-M, Nobile-Orazio E, Cornblath DR, Hadden RDM, Koski L, et al. Multifocal motor neuropathy. In: Gilhus NE, Barnes MR, Brainin M editor(s). European Handbook of Neurological Management. 2nd Edition. Vol. 1, Oxford: WileyBlackwell, 2010:343-50. [MEDLINE: 13080]

\section{Van Swieten 1988}

Van Swieten JC, Koudstaal PJ, Visser MC, Schouten HJ, Van Gijn J. Interobserver agreement for the assessment of handicap in stroke patients. Stroke 1988;19(5):604-7.

\section{References to other published versions of this review \\ Hughes 2012}

Hughes RAC, Mehndiratta MM. Corticosteroids for chronic inflammatory demyelinating polyradiculoneuropathy. Cochrane Database of Systematic Reviews 2012, Issue 8. [DOI: 10.1002/14651858.CD002062.pub2]

\section{Hughes 2015}

Hughes RAC, Mehndiratta MM. Corticosteroids for chronic inflammatory demyelinating polyradiculoneuropathy. Cochrane Database of Systematic Reviews 2015, Issue 1. [DOI: 10.1002/14651858.CD002062.pub3]

\section{Mehndiratta 2001}

Mehndiratta MM, Hughes RAC. Corticosteroids for chronic inflammatory demyelinating polyradiculoneuropathy. Cochrane Database of Systematic Reviews 2001, Issue 3. [DOI: 10.1002/14651858.CD002062]

\section{Mehndiratta 2002}

Mehndiratta MM, Hughes RAC. Corticosteroids for chronic inflammatory demyelinating polyradiculoneuropathy. Cochrane Database of Systematic Reviews 2002, Issue 1. [DOI: 10.1002/14651858.CD002062]

* Indicates the major publication for the study

Dyck 1982

$\begin{array}{ll}\text { Methods } & \text { Parallel group, unblinded quasi-RCT } \\ & \text { Single centre }\end{array}$

Participants
28 people with CIDP according to criteria similar to those of Van den Bergh 2010
Prednisone group $n=14(10 \mathrm{M}$ and $4 \mathrm{~F})$, median age 46.5 years in the prednisone
No steroid control group $n=14(9 M$ and $5 F)$, median age 50 years. See notes 
Dyck 1982 (Continued)

Interventions Prednisone $120 \mathrm{mg}$ every other day tapered to $0 \mathrm{mg}$ in 12 weeks, versus no treatment

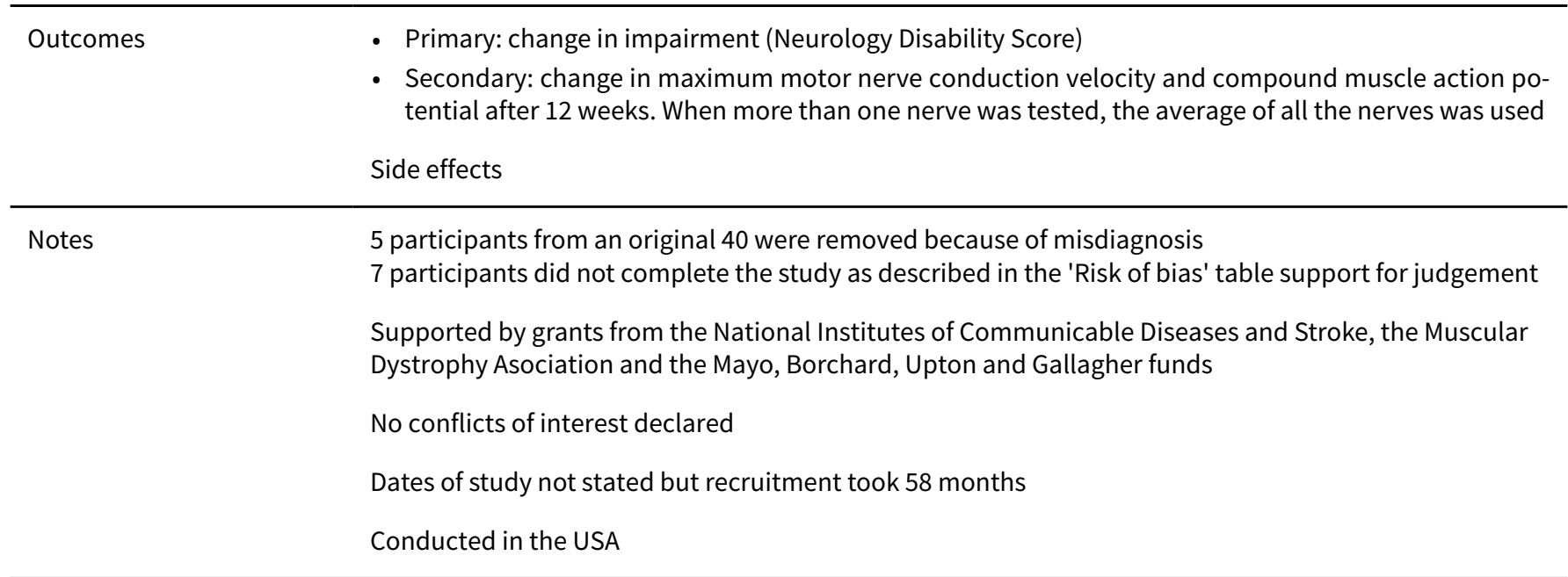

\section{Risk of bias}

\begin{tabular}{lll}
\hline Bias & Authors' judgement & Support for judgement \\
\hline $\begin{array}{l}\text { Random sequence genera- } \\
\text { tion (selection bias) }\end{array}$ & High risk & $\begin{array}{l}\text { People with CIDP who fulfilled the described criteria were matched for age } \\
\text { (18 to } 29 \text { years, } 30 \text { to } 59 \text { years, and over } 60 \text { years) and duration from onset of } \\
\text { symptoms (6 months to } 1.9 \text { years, } 2 \text { to } 3.9 \text { years, and over } 4 \text { years). Male and } \\
\text { female participants were randomly assigned to treatment or no treatment. In } \\
\text { practice, the first participant in each age-duration-sex group was randomly as- } \\
\text { signed to prednisone or no treatment. The second participant in each group } \\
\text { received the alternate therapy, followed by random assignment to the third } \\
\text { participant, and so on }\end{array}$ \\
\end{tabular}

Allocation concealment $\quad$ High risk
(selection bias)

People with CIDP who fulfilled the described criteria were matched for age (18 to 29 years, 30 to 59 years, and over 60 years) and duration from onset of symptoms ( 6 months to 1.9 years, 2 to 3.9 years, and over 4 years). Male and female participants were randomly assigned to treatment or no treatment. In practice, the 1st participant in each age-duration-sex group was randomly assigned to prednisone or no treatment. The 2 nd participant in each group received the alternate therapy, followed by random assignment to the 3rd participant, and so on

\begin{tabular}{lll}
\hline $\begin{array}{l}\text { Blinding of participants } \\
\text { and personnel (perfor- } \\
\text { mance bias) } \\
\text { All outcomes }\end{array}$ & High risk & Comparison of prednisone with no treatment \\
\hline $\begin{array}{l}\text { Blinding of outcome as- } \\
\text { sessment (detection bias) } \\
\text { All outcomes }\end{array}$ & High risk & Comparison of prednisone with no treatment \\
\hline $\begin{array}{l}\text { Incomplete outcome data } \\
\text { (attrition bias) }\end{array}$ & High risk & $\begin{array}{l}\text { All outcomes } \\
\text { not included in the trial analysis. Of } 5 \text { prednisone-treated participants, } 1 \text { died } \\
\text { from cardiac arrhythmia possibly related to hyperglycaemia, } 3 \text { had their pred- } \\
\text { nisone dosage altered from that allowed by the schedule, and } 1 \text { remained de- } \\
\text { pendent on a respirator at another medical centre and could not return for } \\
\text { follow-up. Two participants in the control group were started on prednisone } \\
\text { therapy by their referring physicians because of neurological worsening. Both } \\
\text { were reported to have improved }\end{array}$
\end{tabular}


Dyck 1982 (Continued)

Selective reporting (re- Low risk Nelective reporting identified
porting bias)

Other bias Low risk No other risk of bias identified

\section{PREDICT 2010}

\begin{tabular}{ll}
\hline Methods & Multicentre, double-blind, parallel-group RCT \\
\hline Participants & 40 participants \\
& Dexamethasone group $(\mathrm{n}=24)(18 \mathrm{M}$ and $6 \mathrm{~F})$, mean age 59.9 years \\
& Daily prednisolone group $(\mathrm{n}=16)(10 \mathrm{M}$ and $6 \mathrm{~F})$ mean age 60.8 years \\
& "Patients aged at least 18 years of age with newly diagnosed definite or probable CIDP according to \\
& the European neuromuscular centre diagnostic criteria (Franssen 1997). Patients had to have signs and \\
& symptoms sufficiently severe to warrant treatment and had to be treatment naive. Exclusion criteria \\
& were other diseases known to cause neuropathy (for example diabetes mellitus, paraproteinaemia \\
& (with the exception of an IgG paraproteinaemia of undetermined significance), thyroid disease, vitamin \\
& B1 or B12 deficiency, or significant haematological, renal, or liver disorders); diseases known to lead \\
to reduced mobility, severe handicap, or sudden death; contraindications to corticosteroid therapy; & \\
use of drugs known to cause neuropathy; CSF cell count of more than 30 per mm ${ }^{3}$; and premenopausal \\
women not using a reliable means of contraception. Patients with subacute inflammatory demyeli- \\
nating polyneuropathy or motor CIDP (no sensory signs or symptoms and no abnormalities in sensory \\
nerve conduction studies) were also excluded."
\end{tabular}

Interventions

"Either oral dexamethasone $40 \mathrm{mg}$ per day for 4 days consecutively followed by placebo for 24 days, repeated for six cycles, or daily prednisolone for 32 weeks starting with $60 \mathrm{mg}$ per day for 5 weeks and tapering to alternate day doses and then to zero over the next 27 weeks......Patients on dexamethasone received a cumulative dose of $960 \mathrm{mg}$ dexamethasone equivalent to $6400 \mathrm{mg}$ prednisolone; patients in the prednisolone group received a cumulative dose of $6425 \mathrm{mg}$ prednisolone equivalent to $964 \mathrm{mg}$ dexamethasone."

Outcomes "The primary outcome was the percentage of patients who reached and remained in remission without treatment at 12 months. Remission was defined as improvement of at least three points on the RMI (Collen 1991) and improvement of at least one point on the INCAT disability scale (Hughes 2001) compared with baseline or when the best possible score of a scale had been reached. The RMI ranges from 0 (unable to mobilise) to 15 (fully mobile); the INCAT disability scale ranges from 0 (healthy) to 10 (unable to make any purposeful movements with arms or legs)"

"Secondary outcomes were time to reach remission, number of patients who relapsed within 12 months, time to relapse, number of patients who improved by at least one point on the INCAT disability scale, number of patients who improved by at least three points on the RMI, change in grip strength as assessed with a handheld dynamometer, change in Medical Research Council sum score (range 0-60; including shoulder abduction, elbow flexion, wrist extension, hip flexion, knee extension, and foot dorsiflexion), change in INCAT sensory sum score, change in Short Form-36 Health Survey, and change in ALDS: range 0 (dead) to 100 (fully able)"

Notes

"All patients also received alendronate $10 \mathrm{mg}$ daily or $70 \mathrm{mg}$ weekly to prevent osteoporosis. Daily calcium $1000 \mathrm{mg}$ and vitamin D was added at the discretion of the treating neurologist. After randomisation, patients were not allowed any other immunomodulatory or immunosuppressive treatment until they reached a predefined endpoint"

At each visit adverse events were recorded using a structured questionnaire. Body weight, blood pressure, bone densitometry and eye examination were done at baseline and at endpoint.

Funded by the Prinses Beatrix Fonds and the Department of Neurology, Academic Medical Center. 
PREDICT 2010 (Continued)

No conflicts of interest declared.

Recruitment stopped on 1 December 2007 when 41 of the desired 52 participants had been recruited and final follow-up was on 1 December 2008

Conducted in 8 neuromuscular centres in the Netherlands and one in the UK

\section{Risk of bias}

\begin{tabular}{lll}
\hline Bias & Authors' judgement & Support for judgement \\
\hline $\begin{array}{l}\text { Random sequence genera- } \\
\text { tion (selection bias) }\end{array}$ & Low risk & $\begin{array}{l}\text { The trial pharmacist, who had no further role in the study, randomised each } \\
\text { participant on inclusion. Treatment allocation was performed in a 1:1 ratio by } \\
\text { use of a random number generator. A minimisation procedure was used for } \\
\text { age }(<50 \text { and } \geq 50 \text { years) }\end{array}$ \\
\hline $\begin{array}{ll}\text { Allocation concealment } \\
\text { (selection bias) }\end{array}$ & Low risk & $\begin{array}{l}\text { The trial pharmacist, who had no further role in the study, randomised each } \\
\text { participant on inclusion, and treatment allocation was performed in a } 1: 1 \text { ratio } \\
\text { by use of a random number generator. A minimisation procedure was used for } \\
\text { age }(<50 \text { and } \geq 50 \text { years). Dexamethasone, prednisolone, and placebo came in } \\
\text { identical capsules. After randomisation, the pharmacist delivered trial drugs in } \\
\text { identical white blister packs with the participant's identification number, week } \\
\text { number, and day number on the outside to the trial nurse, who was masked to } \\
\text { treatment allocation. This process ensured concealment of treatment before } \\
\text { allocation. The trial nurse sent the drugs to the various centres by courier. Par- } \\
\text { ticipants and assessors were unaware of the treatment assignment }\end{array}$
\end{tabular}

Blinding of participants Low risk Dexamethasone, prednisolone, and placebo came in identical capsules
and personnel (perfor-

mance bias)

All outcomes

\begin{tabular}{lll}
\hline $\begin{array}{l}\text { Blinding of outcome as- } \\
\text { sessment (detection bias) } \\
\text { All outcomes }\end{array}$ & Low risk & Dexamethasone, prednisolone, and placebo came in identical capsules \\
\hline $\begin{array}{l}\text { Incomplete outcome data } \\
\text { (attrition bias) } \\
\text { All outcomes }\end{array}$ & Low risk & $\begin{array}{l}1 \text { of the } 41 \text { participants withdrew on the day after randomisation due to rapid } \\
\text { progression and change of diagnosis }\end{array}$ \\
\hline $\begin{array}{l}\text { Selective reporting (re- } \\
\text { porting bias) }\end{array}$ & Low risk & No selective reporting identified \\
\hline Other bias & Unclear risk & $\begin{array}{l}\text { Trial stopped early before complete recruitment because of difficulties with re- } \\
\text { cruitment }\end{array}$ \\
\hline
\end{tabular}

ALDS: Academic Medical Center Linear Disability Score

CIDP: chronic inflammatory demyelinating polyradiculoneuropathy

CSF: cerebrospinal fluid

F: female

IgG: immunoglobulin G

INCAT: Inflammatory Neuropathy Cause and Treatment

M: male

$\mathrm{RCT}$ : randomised controlled trial

RMI: Rivermead Mobility Index

\section{Characteristics of excluded studies [ordered by study ID]}




\begin{tabular}{ll}
\hline Study & Reason for exclusion \\
\hline Lopate 2005 & Non-randomised observational study \\
\hline Nobile-Orazio 2012 & $\begin{array}{l}\text { Compared corticosteroids with intravenous immunoglobulin and not with placebo or no treat- } \\
\text { ment. Included in Eftimov } 2013\end{array}$ \\
\hline
\end{tabular}

DATA AND ANALYSES

Comparison 1. Corticosteroids versus control

\begin{tabular}{lllll}
\hline Outcome or subgroup title & No. of studies & $\begin{array}{l}\text { No. of partici- } \\
\text { pants }\end{array}$ & Statistical method & Effect size \\
\hline $\begin{array}{l}1 \text { Improvement in impairment after } 12 \text { weeks } \\
\text { excluding those who did not complete the } \\
\text { study }\end{array}$ & 1 & 28 & $\begin{array}{l}\text { Mean Difference (IV, } \\
\text { Fixed, 95\% Cl) }\end{array}$ & $\begin{array}{l}17.14[-4.39, \\
38.67]\end{array}$ \\
\hline $\begin{array}{l}2 \text { Improvement in impairment after } 12 \text { weeks } \\
\text { including those who did not complete the } \\
\text { study }\end{array}$ & 1 & 35 & Mean Difference (IV, & 11.60 [-9.39, \\
\hline $\begin{array}{l}3 \text { Number of patients improved after } 12 \text { weeks } \\
\text { excluding those who did not complete the } \\
\text { study }\end{array}$ & 1 & $28.58]$ & Fixed, 95\% Cl) \\
\hline $\begin{array}{l}4 \text { Number of patients who showed improve- } \\
\text { ment after } 12 \text { weeks including those who did } \\
\text { not complete the study }\end{array}$ & 1 & Risk Ratio (M-H, & $2.4[1.15,5.00]$ \\
\hline
\end{tabular}

Analysis 1.1. Comparison 1 Corticosteroids versus control, Outcome 1 Improvement in impairment after 12 weeks excluding those who did not complete the study.

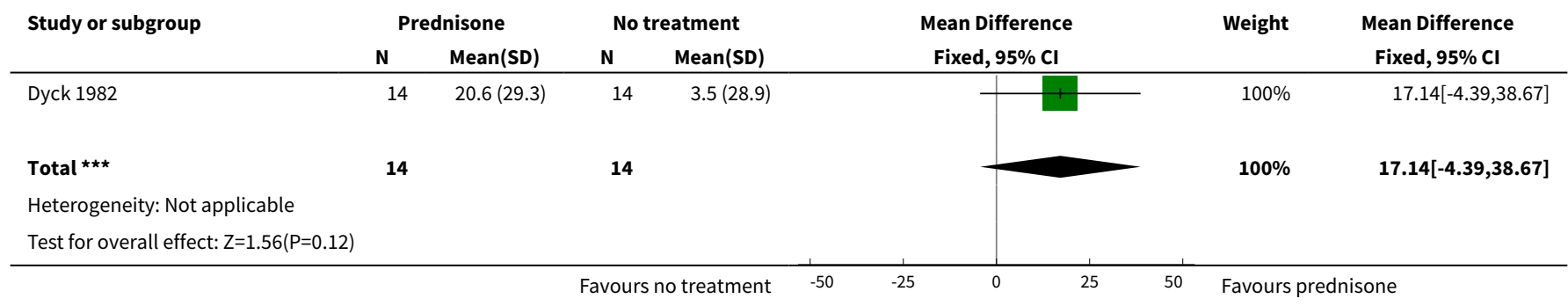


Analysis 1.2. Comparison 1 Corticosteroids versus control, Outcome 2 Improvement in impairment after 12 weeks including those who did not complete the study.

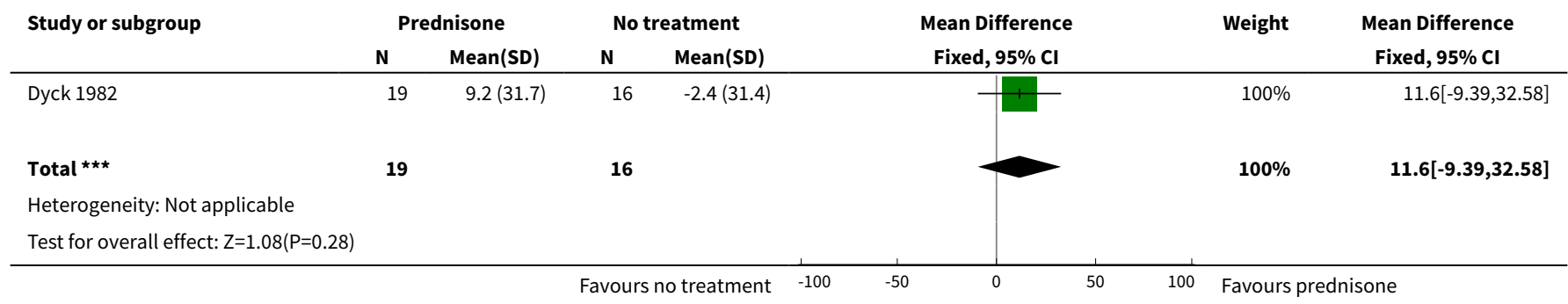

Analysis 1.3. Comparison 1 Corticosteroids versus control, Outcome 3 Number of patients improved after 12 weeks excluding those who did not complete the study.

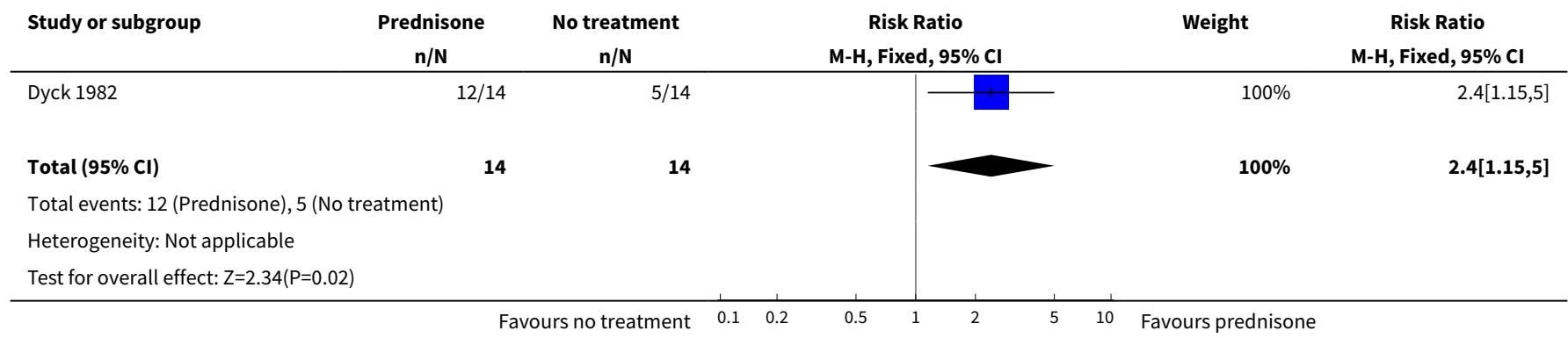

Analysis 1.4. Comparison 1 Corticosteroids versus control, Outcome 4 Number of patients who showed improvement after 12 weeks including those who did not complete the study.

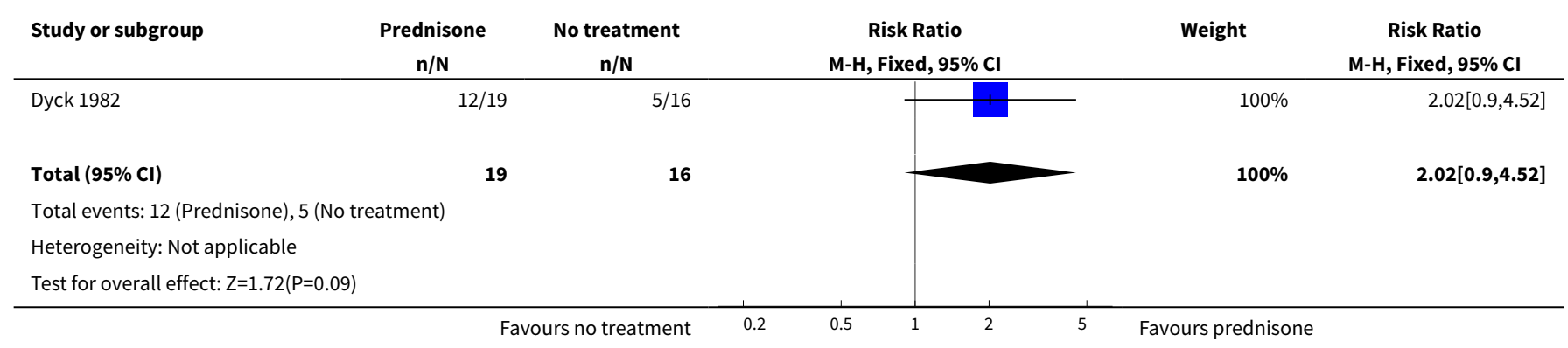

Comparison 2. Standard-dose daily oral prednisolone versus monthly pulsed high-dose dexamethasone

\begin{tabular}{|c|c|c|c|c|}
\hline Outcome or subgroup title & No. of studies & $\begin{array}{l}\text { No. of partici- } \\
\text { pants }\end{array}$ & Statistical method & Effect size \\
\hline $\begin{array}{l}2 \geq 1 \text { point improvement on } \\
\text { INCAT disability score at } 12 \\
\text { months }\end{array}$ & 1 & 40 & Risk Ratio (M-H, Fixed, 95\% Cl) & $1.24[0.64,2.41]$ \\
\hline
\end{tabular}




\begin{tabular}{lllll}
\hline Outcome or subgroup title & No. of studies & $\begin{array}{l}\text { No. of partici- } \\
\text { pants }\end{array}$ & Statistical method & Effect size \\
\hline $\begin{array}{l}\text { 3 Change in MRC sum score at } \\
\text { endpoint }\end{array}$ & 1 & 39 & Mean Difference (IV, Fixed, 95\% Cl) & $2.4[-1.90,6.70]$ \\
\hline $\begin{array}{l}4 \text { Change in grip strength at } \\
\text { endpoint }\end{array}$ & 1 & 38 & Mean Difference (IV, Fixed, 95\% Cl) & $-5.30[-28.43,17.83]$ \\
\hline $\begin{array}{l}5 \text { Sleeplessness } \\
\text { 6 Cushingoid facies }\end{array}$ & 1 & 40 & Risk Ratio (M-H, Fixed, 95\% Cl) & $0.44[0.24,0.84]$ \\
\hline 7 Weight gain 1-3 kg & 1 & 40 & Risk Ratio (M-H, Fixed, 95\% Cl) & $0.5[0.21,1.17]$ \\
\hline 8 Weight gain $>3 \mathrm{~kg}$ & 1 & 40 & Risk Ratio (M-H, Fixed, 95\% Cl) & $0.96[0.55,1.70]$ \\
\hline
\end{tabular}

Analysis 2.1. Comparison 2 Standard-dose daily oral prednisolone versus monthly pulsed high-dose dexamethasone, Outcome 1 Remission at 12 months.

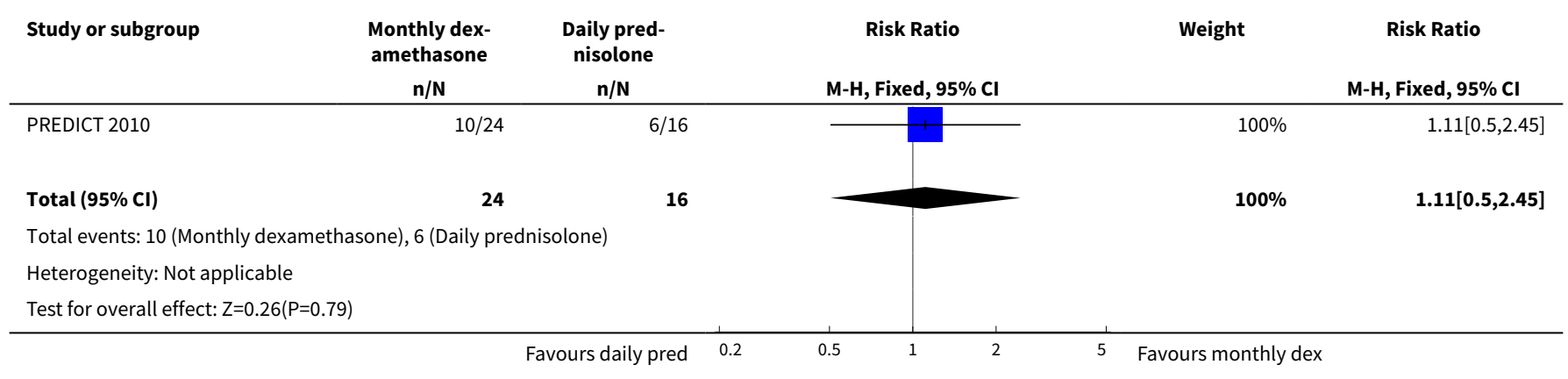

Analysis 2.2. Comparison 2 Standard-dose daily oral prednisolone versus monthly pulsed highdose dexamethasone, Outcome $2 \geq 1$ point improvement on INCAT disability score at 12 months.

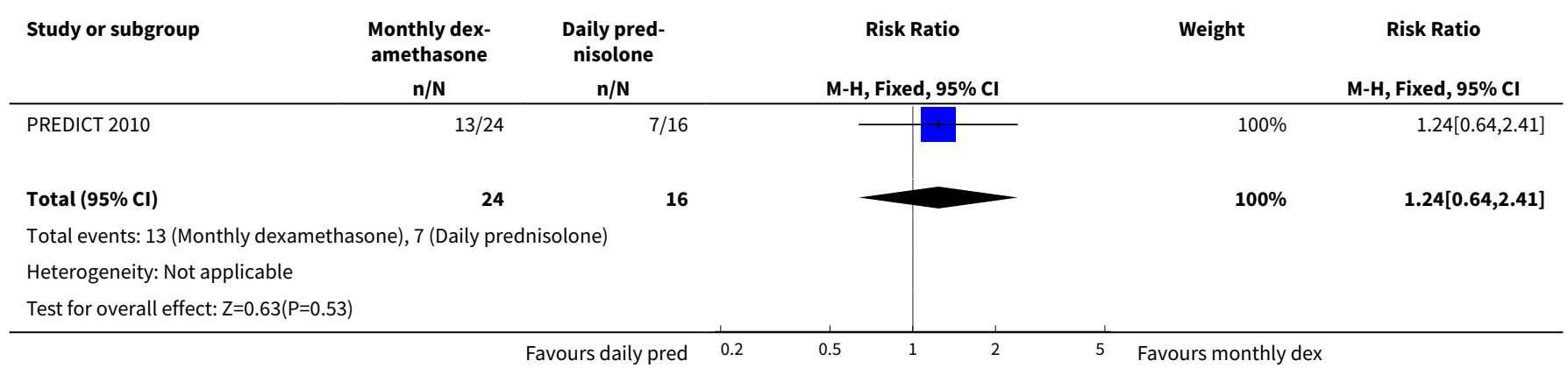


Analysis 2.3. Comparison 2 Standard-dose daily oral prednisolone versus monthly pulsed high-dose dexamethasone, Outcome 3 Change in MRC sum score at endpoint.

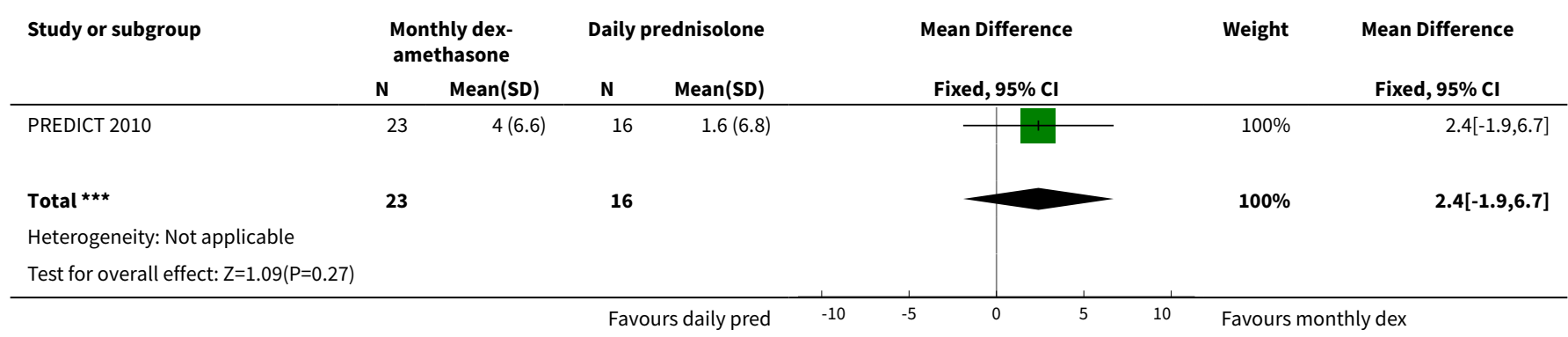

Analysis 2.4. Comparison 2 Standard-dose daily oral prednisolone versus monthly pulsed high-dose dexamethasone, Outcome 4 Change in grip strength at endpoint.

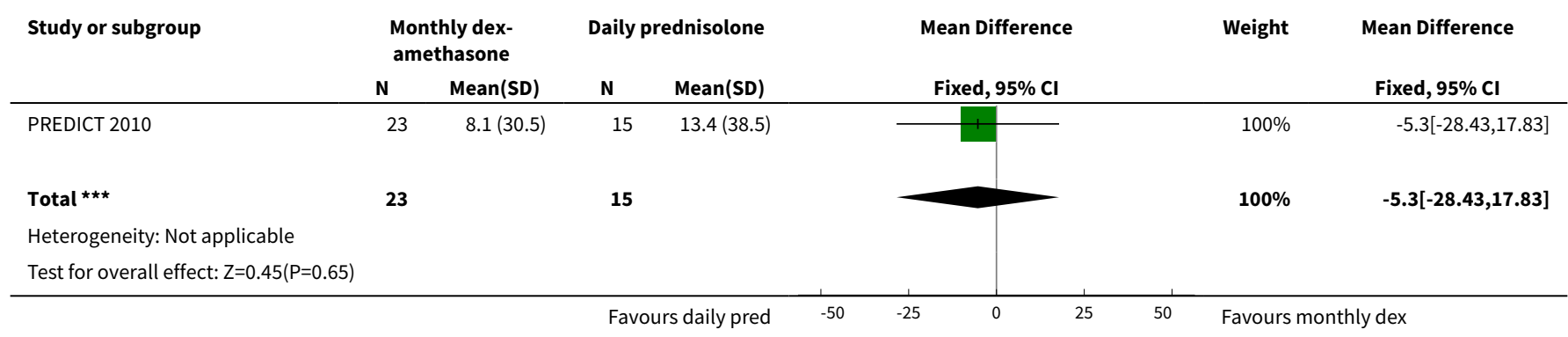

Analysis 2.5. Comparison 2 Standard-dose daily oral prednisolone versus monthly pulsed high-dose dexamethasone, Outcome 5 Sleeplessness.

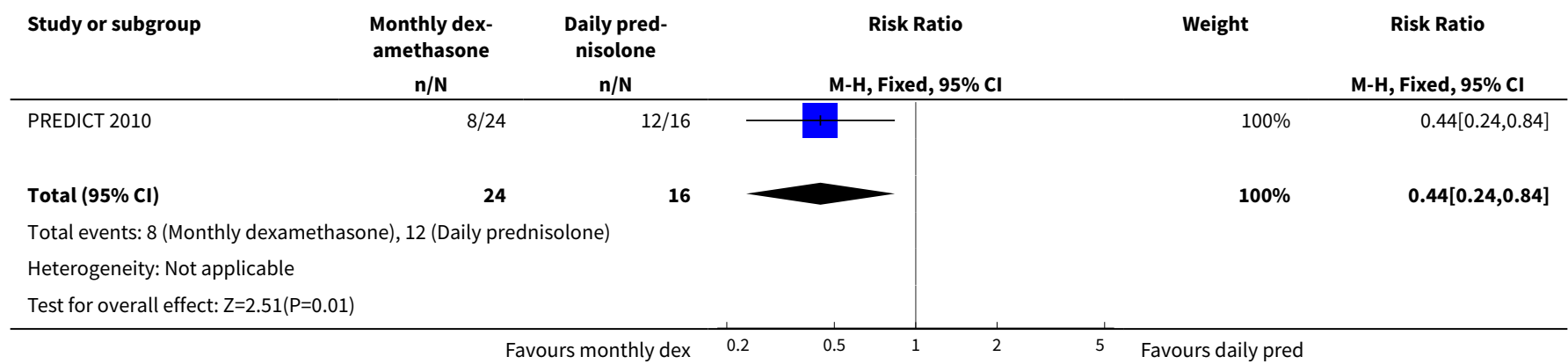

Analysis 2.6. Comparison 2 Standard-dose daily oral prednisolone versus monthly pulsed high-dose dexamethasone, Outcome 6 Cushingoid facies.

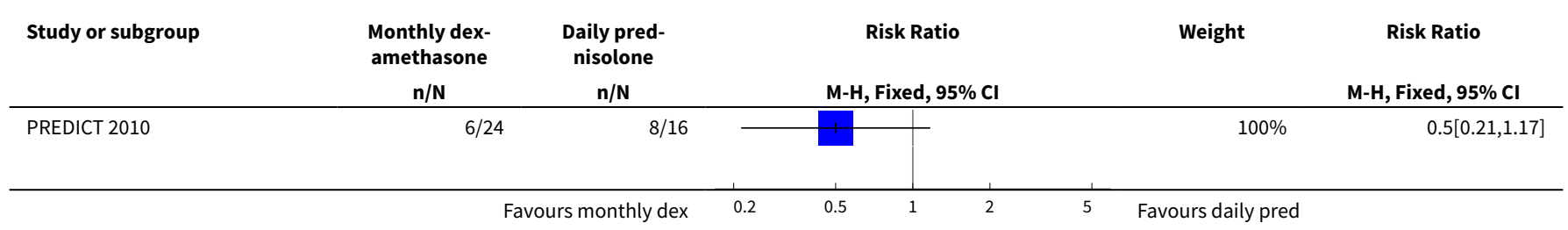




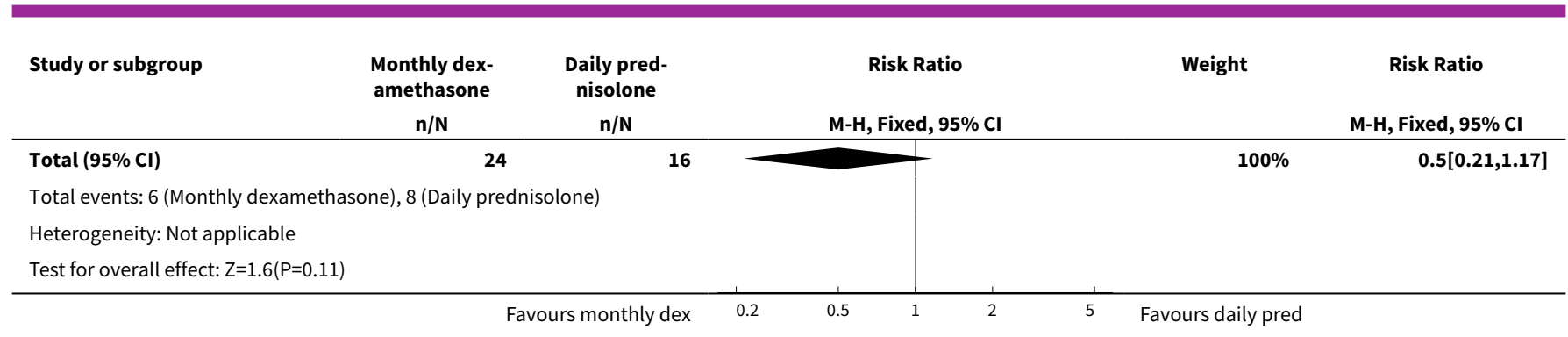

Analysis 2.7. Comparison 2 Standard-dose daily oral prednisolone versus monthly pulsed high-dose dexamethasone, Outcome 7 Weight gain 1 - 3 kg.

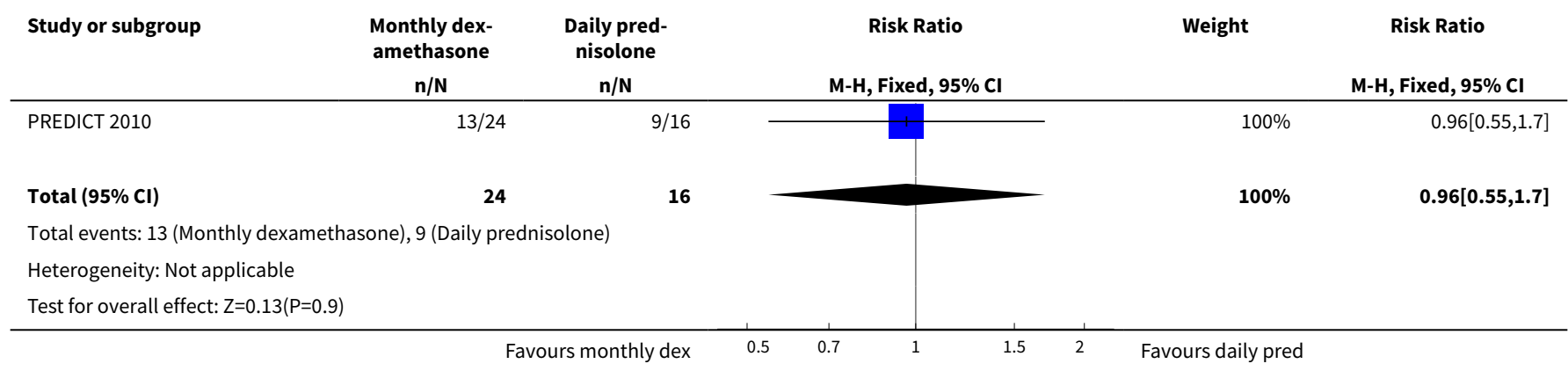

Analysis 2.8. Comparison 2 Standard-dose daily oral prednisolone versus monthly pulsed high-dose dexamethasone, Outcome 8 Weight gain $>3 \mathrm{~kg}$.

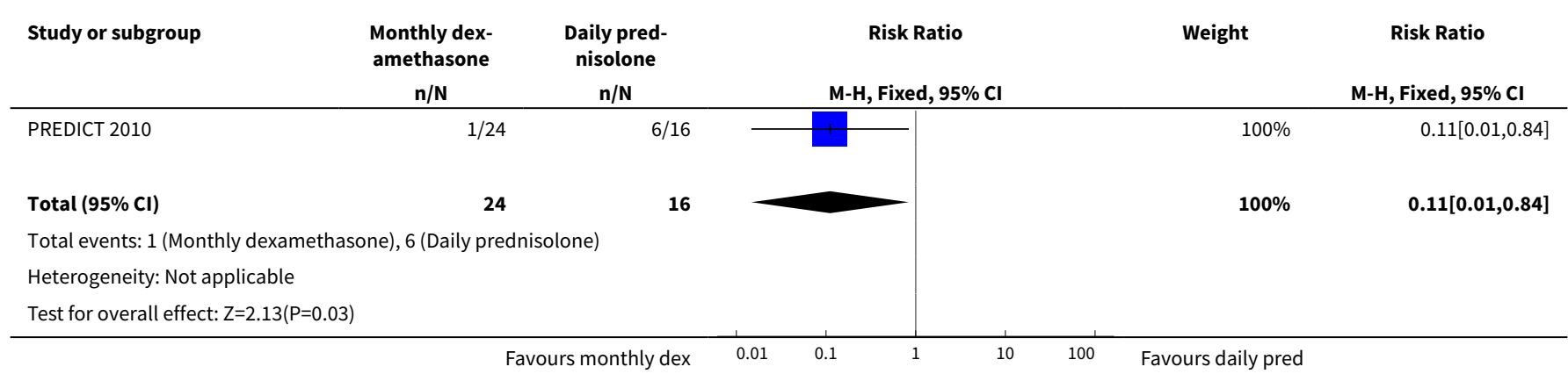

\section{APPENDICES}

\section{Appendix 1. Cochrane Neuromuscular Specialised Register (CRS) search strategy}

\#1 MeSH DESCRIPTOR Polyradiculoneuropathy, Chronic Inflammatory Demyelinating [REFERENCE] [STANDARD]

\#2 (chronic NEAR3 inflammatory NEAR3 demyelinating NEAR3 polyradiculoneuropathy) or (chronic NEAR3 inflammatory NEAR3 demyelinating NEAR3 polyneuropathy) or cidp [REFERENCE] [STANDARD]

\#3 "inflammatory demyelinating" [REFERENCE] [STANDARD]

\#4 polyradiculoneuropathy or polyneuropathy or polyradiculoneuropathies or polyneuropathies [REFERENCE] [STANDARD]

\#5 polyneuritis or polyradiculoneuritis [REFERENCE] [STANDARD]

\#6 MeSH DESCRIPTOR Polyneuropathies [REFERENCE] [STANDARD]

\#7 MeSH DESCRIPTOR Polyradiculoneuropathy [REFERENCE] [STANDARD]

\#8 \#4 or \#5 or \#6 or \#7 [REFERENCE] [STANDARD] 
\#9 "chronic disease" [REFERENCE] [STANDARD]

$\# 10 \# 3$ and \#8 and \#9 [REFERENCE] [STANDARD]

$\# 11 \# 1$ or \#2 or \#10 [REFERENCE] [STANDARD]

\#12 MeSH DESCRIPTOR Adrenal Cortex Hormones Explode All [REFERENCE] [STANDARD]

\#13 MeSH DESCRIPTOR Steroids Explode All [REFERENCE] [STANDARD]

\#14 "adrenocorticotropic hormone*" [REFERENCE] [STANDARD]

\#15 *asone or *olone or *isone or *onide [REFERENCE] [STANDARD]

$\# 16 \# 12$ or \#13 or \#14 or \#15 [REFERENCE] [STANDARD]

$\# 17$ \#11 and \#16 [REFERENCE] [STANDARD]

\#18 (\#11 and \#16) AND (INREGISTER) [REFERENCE] [STANDARD]

\section{Appendix 2. Cochrane Central Register of Controlled Trials (CENTRAL)}

\#1 inflammatory demyelinating

\#2 (polyradiculoneuropath ${ }^{\star}$ or polyneuropath ${ }^{\star}$ )

\#3 MeSH descriptor: [Polyneuropathies] explode all trees

\#4 MeSH descriptor: [Polyradiculoneuropathy] explode all trees

\#5 (polyneuritis or polyradiculoneuritis)

\#6 \#2 or \#3 or \#4 or \#5

\#7 MeSH descriptor: [Chronic Disease] explode all trees

\#8 "chronic disease"

\#9 \#1 and \#6 and (\#7 or \#8)

\#10 chronic inflammatory demyelinating polyradiculoneuropathy

\#11 MeSH descriptor: [Polyradiculoneuropathy, Chronic Inflammatory Demyelinating] explode all trees

$\# 12$ cidp

\#13 \#9 or \#10 or \#11 or \#12

\#14 MeSH descriptor: [Adrenal Cortex Hormones] explode all trees

\#15 "adrenocorticotropic hormone"

$\# 16 \mathrm{MeSH}$ descriptor: [Steroids] explode all trees

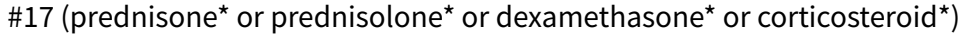

\#18 \#14 or \#15 or \#16 or \#17

$\# 19 \# 13$ and \#18

\section{Appendix 3. MEDLINE (OvidSP) search strategy}

Database: Ovid MEDLINE(R) <1946 to October Week $32014>$

Search Strategy:

1 inflammatory demyelinating.tw. (3256)

2 (polyradiculoneuropath $\$ 3$ or polyneuropath $\$ 3$ ).tw. (11425)

3 polyneuropathies/ or Polyradiculoneuropathy/ (7927)

4 (polyneuritis or polyradiculoneuritis).tw. (1715)

52 or 3 or $4(17287)$

6 Chronic disease/ or "chronic disease".mp. (239755)

71 and 5 and $6(322)$

8 chronic inflammatory demyelinating polyradiculoneuropathy.mp. or Polyradiculoneuropathy, Chronic Inflammatory Demyelinating/ (1215)

9 cidp.tw. (1080)

107 or 8 or 9 (1655)

11 randomized controlled trial.pt. (397325)

12 controlled clinical trial.pt. (90482)

13 randomized.ab. (292700)

14 placebo.ab. (154093)

15 drug therapy.fs. (1776484)

16 randomly.ab. (205493)

17 trial.ab. (304804)

18 groups.ab. (1306164)

19 or/11-18 (3347080)

20 exp animals/ not humans.sh. (4079851)

2119 not 20 (2851539)

2210 and 21 (508)

23 Adrenocorticotropic Hormone/ (44964)

24 exp Adrenal Cortex Hormones/ (345255) 
25 exp Steroids/ (722046)

26 (prednisone or prednisolone\$ or dexamethasone\$ or corticosteroid\$).mp. (195435)

27 or/23-26 (854879)

2822 and $27(221)$

29 remove duplicates from 28 (203)

\section{Appendix 4. EMBASE (OvidSP) search strategy}

Database: Embase <1980 to 2014 Week 43>

Search Strategy:

1 crossover-procedure.sh. (40422)

2 double-blind procedure.sh. (115822)

3 single-blind procedure.sh. (18928)

4 randomized controlled trial.sh. (351750)

5 (random $\$$ or crossover $\$$ or cross over\$ or placebo $\$$ or (doubl\$ adj blind\$) or allocat\$).tw,ot. (1068811)

6 trial.ti. (163787)

7 controlled clinical trial/ (387873)

8 or/1-7 (1304767)

9 exp animal/ or exp invertebrate/ or animal.hw. or non human/ or nonhuman/ (20277690)

10 human/ or human cell/ or human tissue/ or normal human/ (15125106)

119 not 10 (5185248)

128 not 11 (1155248)

13 limit 12 to embase (957660)

14 inflammatory demyelinating.tw. (4862)

15 (polyradiculoneuropath\$3 or polyneuropath\$3).tw. (15663)

16 polyneuropathies/ or Polyradiculoneuropathy/ (13870)

17 (polyneuritis or polyradiculoneuritis).tw. (1614)

1815 or 16 or 17 (22524)

19 chronic disease.mp. or exp Chronic Disease/ (165710)

2014 and 18 and 19 (121)

21 chronic inflammatory demyelinating polyneuropathy/ or chronic inflammatory demyelinating polyradiculoneuropathy.mp. (2440)

22 cidp.mp. (1978)

2321 or $22(3116)$

2420 or $23(3155)$

2513 and 24 (234)

26 exp corticosteroid/ (693539)

27 corticotropin/ (53256)

28 exp steroid/ (1114663)

29 (prednisone\$ or prednisolone\$ or dexamethasone\$ or corticosteroid\$).mp. (494960)

30 or/26-29 (1159921)

3125 and $30(131)$

32 remove duplicates from 31 (131)

\section{Appendix 5. US National Institutes of Health Ongoing Trials Register ClinicalTrials.gov and World Health Organization International Clinical Trials Registry Platform search strategy}

Searched 28 November 2016

Search strategy:

Chronic inflammatory demyelinating polyradiculoneuropathy

\section{WHAT'S NEW}

\begin{tabular}{lll}
\hline Date & Event & Description \\
\hline 8 October 2019 & Amended & $\begin{array}{l}\text { Clarification message added to the Declarations of interest state- } \\
\text { ment about the review's compliance with the Cochrane Com- } \\
\text { mercial Sponsorship Policy. }\end{array}$ \\
\hline
\end{tabular}




\section{HIST O R Y}

Protocol first published: Issue 2, 2000

Review first published: Issue 3, 2001

\begin{tabular}{lll}
\hline Date & Event & Description \\
\hline 2 November 2017 & $\begin{array}{l}\text { New citation required but conclusions } \\
\text { have not changed }\end{array}$ & $\begin{array}{l}\text { No new trials. Discussion revised. GRADE assessments and re- } \\
\text { porting of results revised based on current Cochrane guidance. } \\
\text { Yusuf A Rajabally joined the review at this update. }\end{array}$ \\
\hline 8 November 2016 & New search has been performed & Search updated. \\
\hline 24 November 2014 & $\begin{array}{l}\text { New citation required but conclusions } \\
\text { have not changed }\end{array}$ & Search updated \\
\hline
\end{tabular}

27 October $2014 \quad$ New search has been performed

Plain language summary rewritten. Methods revised to incorporate new outcome measures and diagnostic criteria as stipulated in the 27 April 2012 update. No new studies. Background and discussion revised to incorporate up-to-date references. Results edited to fit latest house style. The search strategies were updated for the October 2014 update to make them more specific. Background and discussion sections revised. No new trials

\begin{tabular}{lll}
\hline 27 April 2012 & $\begin{array}{l}\text { New citation required and conclusions } \\
\text { have changed }\end{array}$ & $\begin{array}{l}\text { Newly included trial has changed conclusions. Updated searches } \\
\text { fully reviewed and incorporated }\end{array}$ \\
\hline 5 March 2012 & New search has been performed & $\begin{array}{l}\text { Searches updated to February 2012. One new trial comparing } \\
\text { two different corticosteroid regimens added. Methods updated } \\
\text { to include 'Risk of bias' and 'Summary of findings' tables. New } \\
\text { references to non-randomised studies added. Text rewritten } \\
\text { throughout }\end{array}$
\end{tabular}

\begin{tabular}{lll}
\hline 26 March 2008 & New search has been performed & $\begin{array}{l}\text { Searches were updated in October 2007. No new relevant trials } \\
\text { were found }\end{array}$ \\
\hline 25 March 2008 & Amended & Converted to new review format. \\
\hline 2 February 2006 & New search has been performed & $\begin{array}{l}\text { The search for randomised trials was repeated on 2nd February } \\
2006 \text { and none were found. }\end{array}$ \\
\hline 1 January 2004 & $\begin{array}{l}\text { New citation required and conclusions } \\
\text { have changed }\end{array}$ & Substantive amendment \\
\hline
\end{tabular}

\section{CONTRIBUTIONS OF AUTHORS}

Two authors (RACH and MMM) extracted data independently. MMM wrote the first draft of the original review. RACH wrote the first draft of the review updates and constructed the 'Risk of bias' and 'Summary of findings' tables. MMM checked the data entry. All three authors agreed the final text of this update.

\section{DECLARATIONS OF INTEREST}

RACH has or has had consultancies with CSL Behring, Grifols, and LFB, companies which produce human immune globulin, and with Novartis which was conducting a trial investigating the immunosuppressive drug fingolimod as a treatment for CIDP. RACH is an honorary member of the Board of GBS CIDP Foundation International, and Medical Patron of gain (Guillain-Barré \& Associated Inflammatory Neuropathies), the British charity which supports people with CIDP. 
YAR has received educational grants from CSL Behring and honoraria for talks from Grifols, Octapharma, CSL Behring, and Kedrion. YAR has received a research grant from LfB France. YAR is secretary of the Medical Advisory Board of gain (Guillain-Barré \& Associated Inflammatory Neuropathies), the British charity which supports people with CIDP.

MMM has no known conflicts of interest.

This review is not compliant with the Cochrane commercial sponsorship policy (as Novartis is a manufacturer of dexamethasone). An update will be planned without conflicted authors.

\section{SOURCES OF SUPPORT}

\section{Internal sources}

- GB Pant Hospital, New Delhi, India.

- King's College London School of Medicine, UK.

\section{External sources}

- The late Mr Chris and Mrs Mary Lazari, UK.

\section{DIFFERENCES BETWEEN PROTOCOLANDREVIEW}

In the original version of this review the primary outcome was change in disability twelve weeks after the start of treatment (Mehndiratta 2001; Mehndiratta 2002), measured by the Modified Rankin Scale (Van Swieten 1988), or a similar disability scale, but the review authors adopted new scales developed for use in CIDP in this and previous updates (Hughes 2012; Hughes 2015).

We added 'Summary of findings' tables. The 'Risk of bias' assessment follows current Cochrane methodology (Higgins 2011). We included a PRISMA flow chart to illustrate the study selection process.

YAR joined the review authors at this update.

\section{N DEX TERMS}

\section{Medical Subject Headings (MeSH)}

Anti-Inflammatory Agents [*therapeutic use]; Dexamethasone [therapeutic use]; Glucocorticoids [*therapeutic use]; Polyradiculoneuropathy, Chronic Inflammatory Demyelinating [ ${ }^{\star}$ drug therapy]; Prednisolone [therapeutic use]; Prednisone [therapeutic use]; Randomized Controlled Trials as Topic

\section{MeSH check words}

Humans 